\title{
A Comprehensive Review and Qualitative Analysis of Micro-Combined Heat and Power Modeling Approaches ${ }^{\dagger}$
}

\author{
Praveen Cheekatamarla *(D) and Ahmad Abu-Heiba \\ Building Equipment Research Group, Energy and Transportation Science Division, Oak Ridge National \\ Laboratory, Oak Ridge, TN 37831, USA; abuheibag@ornl.gov \\ * Correspondence: cheekatamapk@ornl.gov; Tel.: +1-865-341-0417 \\ † This manuscript has been authored by UT-Battelle, LLC under Contract No. DE-AC05-00OR22725 with the \\ U.S. Department of Energy. The United States Government retains and the publisher, by accepting the article \\ for publication, acknowledges that the United States Government retains a non-exclusive, paid-up, \\ irrevocable, world-wide license to publish or reproduce the published form of this manuscript, or allow others \\ to do so, for United States Government purposes. The Department of Energy will provide public access to \\ these results of federally sponsored research in accordance with the DOE Public Access Plan \\ (http://energy.gov/downloads/doe-public-access-plan).
}

Received: 9 May 2020; Accepted: 8 July 2020; Published: 11 July 2020

check for updates

\begin{abstract}
Concurrent production of electrical and thermal energy from a Combined Heat and Power $(\mathrm{CHP})$ device is an attractive tool to address the growing energy needs of the planet. Micro CHP $(\mu \mathrm{CHP})$ systems can reduce a building's primary energy consumption, reduce carbon footprint, and enhance resiliency. Modeling of the $\mu \mathrm{CHP}$ helps understand the system from multiple perspectives and helps discover errors earlier, improves impact analysis and simulation of system solutions for ease of integration with the building. Consequently, there is a need for analysis of the impact of $\mu \mathrm{CHP}$ modeling approach on its reliability and flexibility. The primary objective of this paper is to review the state-of-the art models in the $\mu \mathrm{CHP}$ space with a focus towards internal combustion engine as the primary mover (PM) and limit the study to system modeling, calibration, and validation methodologies. Based on the analysis, recommendations for further model considerations and refinements are presented.
\end{abstract}

Keywords: micro combined heat and power; cogeneration; engine; modeling; prime mover

\section{Introduction}

The technical potential energy savings of distributed generation (DG) in the US is significant. This potential, however, remains mostly untapped in building applications. Micro Combined Heat and Power $(\mu \mathrm{CHP})$ systems in a DG infrastructure can reduce a building's primary energy consumption, reduce carbon footprint, and enhance resiliency. The simultaneous production of electrical and thermal energy from a single fuel source at a high overall energy efficiency can reduce primary energy consumption while lowering greenhouse gas (GHG) emissions. The decentralized aspect of these $\mu \mathrm{CHPs}$ can potentially reduce distribution losses while reducing the peak load burden on central power generation plants. Economic and population growth are the primary drivers of rising electricity demand and it is bound to increase further, especially as electric vehicles become commonplace. In fact, CHP technology is gaining ground as an acceptable energy provider at university campuses, industrial facilities, and as backup generation, according to a recent study [1]. The key market drivers contributing towards the growth of $\mathrm{CHP}$ technologies include lower operating costs, environmental regulations, resiliency, policy support, reliability, and utility interest. CHP reduces the burden on 
electric grid as well as the need for new transmission and distribution infrastructure while utilizing domestically available clean energy resources such as biomass and natural gas. Some of the major hurdles for the mass deployment of CHPs include value proposition to the utilities, user awareness, permitting and siting constraints, and general market uncertainties.

Cogeneration technologies including those of industrial and micro scale have been analyzed for their applications in buildings dating back to late 20th century [2]. The authors identified the hurdles for rapid deployment and adoption by utilities, industries, and governmental regulatory bodies. Suggestions were made for accelerating the implementation of these devices with a primary focus on research, fuels, economics, environment, industry-utility interface, and regulation. Some of these focal points are still relevant even though the suggestions were made almost four decades ago!

The next wave of activity in the CHP area began around 17 years ago when the International Energy Agency (IEA) initiated a large-scale international effort (with 25 participating countries) in developing a simulation model for investigating the performance of cogeneration devices serving residential buildings. This effort was taken up under Annex 42 in IEA's Energy Conservation in Buildings and Community Systems (ESBCS) Program [3]. A detailed review of this model will be presented in the next section.

Given the significant potential of $\mu \mathrm{CHP}$ in buildings, we present in this paper a review of prior work in modeling $\mu \mathrm{CHPs}$ that use internal combustion engine (ICE) as the primary mover. ICE-based $\mu \mathrm{CHPs}$ are attractive since the primary power source technology is mature and offers numerous advantages viz. cost and reliability, compared to the other power generation schemes including emerging technologies. Evolution of the ICEs in improving the electrical energy efficiency and its potential for low cost manufacturing are some of the key elements which make it an attractive option for large scale application in a DG architecture.

Integration of these $\mu \mathrm{CHP}$ units as primary building energy resources requires good understanding of their performance in meeting the dynamic energy needs (thermal and electric loads) of the building influenced by users, seasons, climate, and the overall interaction with the grid. Actual savings to the user such as energy consumption minimization and optimal economic benefits are highly dependent on the sizing, control scheme, and user demand fitting. In light of this, a reliable global dynamic model of the $\mu \mathrm{CHP}$ system is absolutely necessary for design, integration and implementation considerations in buildings. The key elements of the $\mu \mathrm{CHP}$ include prime mover, heat exchanger, energy storage, and the control system. All these elements must be defined in both steady state and transient modes and accounted for in the global $\mu \mathrm{CHP}$ model.

The primary modeling approach generally falls in to one of three categories viz.: (i) Standard system model where all the system subcomponents are solved consecutively, offering simplicity but little flexibility in wider adoption (ii) flexible component based modular approach where the major functional components can be refined by customizing and providing necessary input and output data, and (iii) differential equation based approach where the individual objects are represented by expressions with time as an independent variable, offering high level of flexibility but significant upfront processing for executing the developed algorithm. Thermal simulation of the $\mu \mathrm{CHP}$ can be studied as a steady-state system however the practical application of such systems is highly dynamic in nature and hence transient processes involved in the global operations of each major subcomponent must be thoroughly considered.

In this framework, this paper presents a comprehensive overview of various modeling approaches adopted by international researchers. A review of the modeling scheme of $\mu \mathrm{CHP}$ along with various steps involved in the calibration was extensively discussed in a previous paper published in the year $2007[3,4]$. The primary goal of the present paper is to review and discuss latest approaches in $\mu \mathrm{CHP}$ (after year 2007) modeling. The key objective is to present the state-of-the-art thermodynamic models and their advantages, while identifying opportunities for further refinement to expand the capabilities of such models for versatile applications and ability to accept different prime power ICE based $\mu \mathrm{CHP}$ products. The paper will identify the key thrust areas in the prior work with a focus towards dynamic 
modelling approach. Standalone and hybrid ICE-based $\mu \mathrm{CHP}$ modeling strategies and integration considerations have been reviewed, primarily in residential and commercial scale building applications along with energy storage. The key focus is to provide an overview of the modeling considerations when designing a $\mu \mathrm{CHP}$ system with ICE as the PM, to address the desired thermal and electrical load demands when utilized with energy storage modules. PMs other than internal combustion engines were not considered in this study. Excluded from this study are the economic modeling aspects, interactions between these distributed generation sources and the grid network as well as the building types, envelope related factors, and climate zones.

\section{Review of the Models}

Several researchers investigated the dynamics of multiple cogeneration $/ \mu \mathrm{CHP}$ systems powered by different fuels (both fossil and renewable) and power sources (turbine, ICE, Stirling engines, SOFCs, PEMFCs, concentrated solar, etc.) via modeling approaches developed independently as well as Annex 42-based analysis. The following sections elaborate different modeling strategies.

\subsection{Annex 42 Models}

IEA sponsors research and development in numerous energy-related areas. The ECBCS program of IEA facilitates the acceleration and introduction of energy conserving and sustainable technologies for applications in healthy buildings and communities. Annex 42 of this program focused on developing simulation models for systems up to $15 \mathrm{~kW}$, to advance the residential cogeneration systems and assess techno-economic-environmental performance. This effort [3] initially reviewed the $\mu \mathrm{CHP}$ performance assessment studies at the time (2007), including experimental tests, methodologies and modeling techniques utilized. This review visited the $\mu \mathrm{CHP}$ modeling work performed at various institutions globally, a selected few are mentioned here. A techno-economic and environmental assessment of five different $<5 \mathrm{~kW} \mu \mathrm{CHPs}$, based on internal combustion engines, Stirling engines and fuel cells in residential buildings was conducted. The authors concluded that primary energy savings and carbon dioxide reductions are possible with the studied devices however a significant mismatch between electrical loads and the total power production was recognized [4]. Similarly, Dorer et al. applied a simulation methodology to identify the important influencing factors affecting the $\mu \mathrm{CHP}$ 's performance and its result on primary energy demand and emissions [5]. In a separate study, Wu et al. reviewed different tri-generation system configurations and the key influencing factors for wider adoption of the technologies [6]. Preliminary investigation of a novel hybrid heat pump based combined heat and power device was conducted by Few et al. The authors concluded that the heat pump improves the overall efficiency while offering significant flexibility in managing the energy needs [7]. A comparison of electrical and thermal load following $\mu \mathrm{CHP}$ system models showed that the thermal load following configuration offered higher overall efficiency and economic benefit [8]. In a similar study, control strategies to manage $\mu \mathrm{CHP}$ systems was suggested to minimize the supply vs. demand challenges [9]. Integration of CHP with renewable energy sources such as wind was modelled [10]. A comprehensive framework for uncertainty analysis was presented in an integrated approach using residential distributed energy resources utilizing energy storage [11,12].

The authors reviewed and concluded that there was a lack of cogeneration device models suitable for whole building simulation programs. It was also concluded that $\mu \mathrm{CHP}$ system studies showed reductions in non-renewable primary energy demand compared to conventional gas boiler systems and grid electricity as the benchmark. Based on the review of the state-of-the-art models, the authors concluded that the control mode plays a significant role in $\mu \mathrm{CHP}$ system's performance, where heat load following offers best energy efficiency, while electricity load following reduced cost.

Annex 42's modeling approach included identification of physical characteristics of the device, development and verification of engineering model, followed by developing module of the model in a building simulation tool. The primary objective of this approach was to develop a model that is suitable for coupling the performance of the cogeneration unit with building model. The model 
contains discrete control volumes and input parameters that can be adjusted to simulate a variety of devices. The model is simplified and parametric in nature to meaningfully study the interactions between a cogeneration system and the building.

The engineering model considered three primary control volumes [13]: (1) Energy conversion control volume representing the engine working fluids and the electric generation device (ICE), (2) Engine control volume representing the thermal mass of the engine and its internal heat exchangers, and (3) Coolant control volume representing the flow of the engine coolant and the thermal mass of the heat exchange components in immediate contact with the coolant. The energy flows among the three control volumes are illustrated in Figure 1.

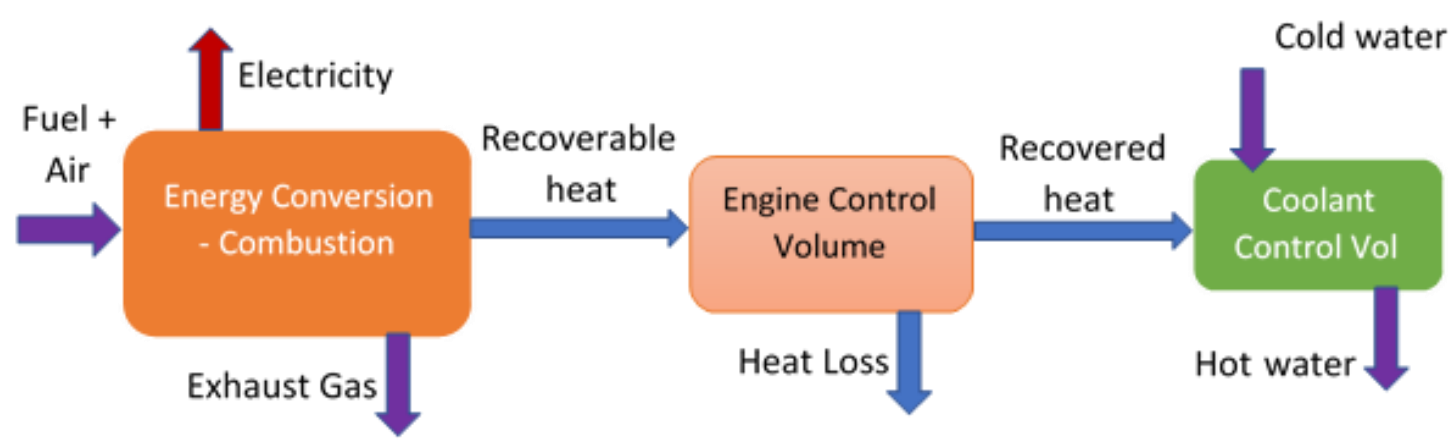

Figure 1. Generic engine model control volumes, Annex 42 modeling strategy (IEA ECBCS Program).

Mass transfer in purple and heat transfer in blue.

The adopted modeling strategy captured different energy exchanges in the performance map with empirical correlations describing the part-load electrical and thermal efficiencies, and the cogeneration system's steady-state behavior under a variety of loading conditions. The development of the model is detailed in [13]. Here, we will only summarize the key equations that simulate the thermal performance of the $\mu \mathrm{CHP}$. The model starts with known electric output, $P_{n e t}$, and the temperature of the cooling water to the cooling water control volume, $T_{c w, i}$. The model then uses a correlation for fuel-to-electric conversion efficiency, $\eta_{e}$, to calculate the fuel consumption of the engine, $Q_{g r o s s}$, as in Equation (1):

$$
Q_{g r o s s}=\frac{P_{n e t}}{\eta_{e}}
$$

The efficiency, $\eta_{e}$, is a function of the flow rate of the cooling water, $m_{c w}$, the temperature of the cooling water at the inlet to the cooling water control volume, $T_{c w, i}$, and the electric demand. The authors suggested a tri-variate second-order polynomial form as in Equation (2):

$$
\eta_{e}=\sum_{i=0}^{2} \sum_{j=0}^{2} \sum_{k=0}^{2} a_{i j k} P_{n e t}^{i} T_{c w, i}^{j} m_{c w}^{k}
$$

To calculate the recoverable heat, an efficiency parameter, $\eta_{q}$, is defined as the ratio of recoverable heat to the fuel consumption of the engine. The authors suggested a form similar to $\eta_{e}$ as shown in Equation (3):

$$
\eta_{q}=\sum_{i=0}^{2} \sum_{j=0}^{2} \sum_{k=0}^{2} b_{i j k} P_{n e t}^{i} T_{c w, i}^{j} m_{c w}^{k}
$$

The recoverable heat, $Q_{g e n}$, is then calculated as in Equation (4):

$$
Q_{g e n}=\eta_{q} Q_{\text {gross }}
$$


A portion of the recoverable heat is lost to ambient, $Q_{\text {loss }}$, and is assumed to be proportional to the difference between the bulk average engine temperature, $T_{e}$, and the temperature of the surrounding ambient, $T_{a}$, as in Equation (5):

$$
Q_{\text {loss }}=[U A]_{\text {loss }}\left(T_{e}-T_{a}\right)
$$

$[U A]_{\text {loss }}$ is the overall effective thermal conductance between the engine control volume and the surroundings. Another portion of the recoverable heat is recovered into the cooling water stream, $Q_{H X}$. This portion is calculated based on an overall thermal conductance between the cooling water and the engine, $[U A]_{H X}$, as in Equation (6):

$$
Q_{H X}=[U A]_{H X}\left(T_{e}-T_{c w, o}\right)
$$

$T_{c w, o}$ is the temperature of the cooling water at the outlet of the cooling water control volume. An energy balance is then performed on the engine control volume as in Equation (7) and the cooling water control volume as in Equation (8):

$$
\begin{gathered}
{[M C]_{e} \frac{d T_{e}}{d t}=Q_{g e n}-Q_{H X}-Q_{\text {loss }}} \\
{[M C]_{c w} \frac{d T_{c w}}{d t}=m_{c w} C_{c w}\left(T_{c w, i}-T_{c w, o}\right)+Q_{H X}}
\end{gathered}
$$

$[M C]_{e}$ is the bulk thermal capacitance of the engine block and its internal heat exchangers. $[M C]_{c w}$ is the overall thermal capacitance of the encapsulated cooling water in the system and the heat exchangers in immediate contact with the encapsulated cooling water. $C_{c w}$ is the specific heat of the cooling water. $T_{c w, i}$ is the temperature of the cooling water at the inlet to the cooling water control volume.

The use of this model requires its calibration first: that is the knowledge of the $a$ coefficients of $\eta_{e}$, the $b$ coefficients of $\eta_{q},[U A]_{l o s s},[U A]_{H X},[M C]_{e}$ and $[M C]_{c w}$. These parameters however are not easy to calculate and in most, or all, cases these parameters will have to be estimated empirically.

Several operating modes including standby, warmup, cool-down as well as scenarios with switching between these modes were also considered by the authors [13]. Additionally, the model also accounted for low level controls such as system level internal control protocol for safe operation. The high-level controls account for system's interaction with external building controls including electrical interface, control signal interface, control flags, and other data output. The simulation environment also considered external environmental boundary conditions including ambient air temperature, cooling water temperature, and cooling water mass flow rate for the engine and coolant control volumes.

The model developed under Annex 42 program was later integrated into various simulation tools (e.g., EnergyPlus, TRNSYS, ESP-r) to provide coupling between the cogeneration device and the building's thermal/electric demands. The developed model was calibrated experimentally followed by validation and performance assessment [13]. In this study, several experiments were conducted using early market residential cogeneration prototypes, guided by the interests and resources available to the participants. The combustion cogeneration devices used in the calibration studies restricted the use of invasive instrumentation, hence the calibration process was carried out using a methodology capable of deriving multiple model inputs from a limited set of measurements collected during dynamic testing as well as manufacturer's literature. Data from the extended performance testing was utilized as quasi-steady state conditions. Uncalibrated model inputs were determined by comparing model's predictions to the dynamic performance observed in the prototypes. Third party optimization utilities were finally used to identify the rest of the calibration parameters, for instance, considering the difference between measured and predicted values.

Beausoleil-Morrison et al. [3,5,13] developed a detailed experimental protocol to calibrate the Annex 42 model. The authors then presented a calibration of the model for a commercially available 
$5.5 \mathrm{~kW} / 12.5 \mathrm{~kW}_{\mathrm{t}}$ ICE cogeneration device and later validated the model. The calibration and validation used datasets from an installation that did not follow the experimental protocol but nevertheless provided rich data for calibration and validation. The coefficients of both $\eta_{e}$ and $\eta_{q}$ were determined from steady state measurements at different levels of electric power demand, cooling water flow rates and cooling water inlet temperature. The influence of cooling water temperature and cooling water flow rate on $\eta_{e}$ and $\eta_{q}$ was considered to be insignificant. The thermal capacitances ([MC] values) and the thermal conductance ([UA] values) were estimated using parameter identification process. The boundary and initial conditions were fed to the model and the outputs were compared to the actual data. The $[\mathrm{MC}]$ and $[\mathrm{UA}]$ values were varied to minimize the error between the model output and the actual data. This study used a generic platform independent optimization program, GenOpt to determine the $[\mathrm{MC}]$ and $[\mathrm{UA}]$ values. GenOpt enables automatic optimization using advanced search techniques to determine optimal design parameters by minimizing the cost function. GenOpt drove the simulation software incorporating the customized cogeneration device model over multiple simulations. The power output required from the generator, the coolant inlet mass flow rate and coolant temperature were derived from experimental data and used as inputs to the simulation model. The target optimization parameter was the cooling water outlet temperature, as it was the principal coupling variable between the cogeneration model and the integrated system model. The calibration parameters are summarized in Table 1.

Table 1. Calibration parameters reported in $[5,13]$ for $5.5 \mathrm{~kW}_{\mathrm{e}} / 12.5 \mathrm{~kW}$ single-speed ICE $\mu \mathrm{CHP}$.

\begin{tabular}{cccc}
\hline$\eta_{e}$ & 0.27 & $\eta_{q}$ & 0.66 \\
\hline$[U A]_{\text {loss }}$ & $13.7 \mathrm{~W} / \mathrm{K}$ & {$[U A]_{H X}$} & $741 \mathrm{~W} / \mathrm{K}$ \\
\hline$[M C]_{e}$ & $63,605.6 \mathrm{~J} / \mathrm{K}$ & {$[M C]_{c w}$} & $1000.7 \mathrm{~J} / \mathrm{K}$ \\
\hline
\end{tabular}

Ferguson et al. who participated in the Annex 42 program later investigated the model's reliability by using a comprehensive comparative testing suite of all three simulation programs (EnergyPlus, TRNSYS, ESP-r) and validated them using measured data [14]. The Annex 42 model did not employ analytical validation due to the complex nature of cogeneration devices but rather utilized empirical validation and comparative testing. Hence the researchers pursued the comparative testing first by utilizing equivalent inputs and boundary conditions across all three simulation platforms using a test suite comprising of 44 cases, in order to identify implementation errors. The calibration data was derived from previous experimental studies [13] via an iterative approach as the original tests were not designed to be compatible with the Annex 42 model. The empirical validation study later proved the model's suitability for representing a real-world cogeneration system. The comparison with experimental data was pointed to be valid only under non-condensing operation as the calibration was performed under such a condition. The Annex 42 model however accounts for condensing operation by implicitly accounting for in the engine performance equations.

IEA's Annex 42 combustion simulation model was calibrated and validated using a $6 \mathrm{~kW}_{\mathrm{e}} / 11.5 \mathrm{~kW}_{\mathrm{t}}$ natural gas fueled $952 \mathrm{~cm}^{3}$ reciprocating ICE $\mu \mathrm{CHP}$ [15] capable of modulating its output. The thermal recovery from the water-glycol coolant mixture was accomplished in a plate heat exchanger and stored in a water tank. The stored heat was directly utilized for building heating during the winter while indirectly utilized for cooling via a lithium chloride absorption heat pump during the warm season, as shown in Figure 2 below. Rosato et al. conducted a thorough experimental campaign under a range of controlled boundary conditions to generate a data set encompassing both steady-state and transient operational scenarios. Hundred and three empirically derived coefficients were acquired from the calibration tests and used as inputs to the model, specific to the prime mover investigated. The key approach included measuring primary energy consumption, electric power production and thermal output to generate calibration data for the model. Detailed calibration procedures to determine the 103 model parameters were described. 


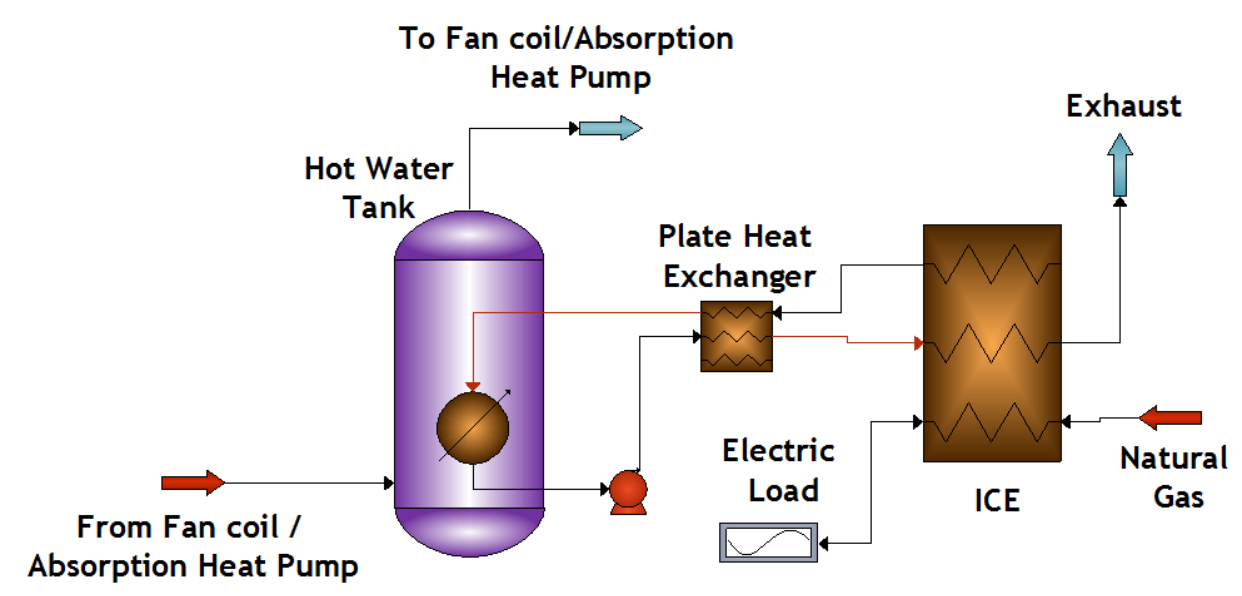

Figure 2. Scheme of experimental apparatus of an ICE-based $\mu \mathrm{CHP}$.

Discrepancies between the model structure and the experimental behavior were highlighted and some modifications to the mathematical form of the Annex 42 were suggested by Rosato et al. In one such discrepancy for instance, the model assumes no fuel consumption and heat generation during cool down in contrast with the experimental behavior of the tested engine. Specific limitations of the Annex 42 model for the treatment of steady-state and transient modes of operation were also highlighted. For example, the Annex 42 model assumes that the $\mu \mathrm{CHP}$ transitions from cool-down to normal mode via warm-up sequence, however, the investigated $\mu \mathrm{CHP}$ transitioned directly to the normal mode without going through the warm-up state. Another discrepancy was also identified in the study, where the influence of engine temperature on warm-up time was ignored by the model and the authors considered the longest warmup time for the calibration data. Further experiments were later conducted with different boundary conditions to validate the calibrated model. The adopted experimental scheme is shown in Figure 2 below. The apparatus had the ability to operate in either electric or thermal load following with optional heat rejection in case of overheating of the hot water storage tank.

The authors noticed that the fuel usage, electric output and heat recovery were slightly under-predicted by $1-6 \%$ compared to experimental data. Despite these transient discrepancies, the investigation concluded that the Annex 42 model was reliable in accurately predicting both the steady state and dynamic response of the tested cogeneration unit.

The same authors expanded the work to evaluate the influence of transient periods in assessing an ICE based $\mu \mathrm{CHP}$ unit's performance [16]. The authors concluded that the transient behavior had negligible impact on electric power generation and fuel consumption prediction by the model. However, due to the slow transient heating of the engine, the authors pointed that neglecting the influence of thermal transition can overestimate the thermal output from the unit. This factor was suggested to be significant at lower outputs (or lower load points). A revised experimental plan was proposed to properly calibrate the model parameters in order to assess its reliability for evaluating and predicting the system operation under various load conditions. The approach extended the time of normal mode operation until $>95 \%$ of the maximum $\mu \mathrm{CHP}$ efficiency (both thermal and electric) was achieved. Using the revised calibration parameter values improved the model's predictability of the unit's performance.

The Annex 42 model was again utilized to study the performance of an ICE based $6 \mathrm{~kW}_{\mathrm{e}}$ residential building integrated micro-cogeneration system operated during the heating season using the TRNSYS dynamic platform [17]. This study comprised of a CHP system supported by heat exchangers and auxiliary boilers. Parametric analysis of the system was conducted in a similar fashion as that utilized by Rosato et al. [15]. Additionally, the model was integrated with hot water storage tank model, boiler model, and subjected to analysis in different building types and climatic zones while supporting 
electric, space heating and water heating loads. Primary energy savings were analyzed as a function of electric and thermal load following scenarios and concluded that a larger thermal energy storage tank was necessary to optimize the efficiency under any operating mode.

A separate study focusing on this thermal energy storage aspect was conducted by German researchers where the research team investigated the capacity model and stratification model to allow the $\mu \mathrm{CHP}$ system to operate in electric load following mode [18].

In conclusion, the Annex 42 modeling strategy has been successfully adopted by several researchers in estimating the $\mu \mathrm{CHP}$ 's electrical and thermal efficiencies under a wide range of operating conditions. Different shortcomings were identified and rectified in accurately predicting the performance of an integrated $\mu \mathrm{CHP}$, as discussed above.

\subsection{Independent Models}

Several researchers developed and studied customized approaches and models suitable for $\mu \mathrm{CHP}$ configurations and operating regimes, independent of the Annex 42 model. The following discussion reviews these modeling strategies.

Modeling of a $\mu \mathrm{CHP}$ system was conducted using high resolution experimental results from a single cylinder natural gas fueled $4 \mathrm{~kW}_{\mathrm{e}}$ Otto cycle engine [19]. The research team developed and tuned the model to match steady state test results followed by validation with transient experiment results. The effect of regional variation, and the impact of thermal energy storage were also investigated. The test unit consisted of several heat exchangers connected in series and finally integrated with hot water storage tank via a plate heat exchanger. The engine was modeled using type 907 component in TRNSYS using empirical performance data to determine the operating outputs. The desired electric output derived the efficiency, and exhaust quality using the performance map. Schematic of the laboratory $\mu \mathrm{CHP}$ system configuration utilized in this study are shown in Figure 3 below. In addition to the PM, this work modeled the storage tank as a fluid filled constant volume tank divided into isothermal temperature nodes to simulate the stratification environment. Thermal loss from the tank to ambient was determined through empirical data at fully heated state. Experimental results were used for the steady state calibration by operating the PM at fixed speed while discarding the heat to the outdoors. Validation experiments revealed a $1.7 \%$ deviation in the observed thermal output and considered satisfactory, given the measurement uncertainty and approximations for exhaust gas specific heat values.

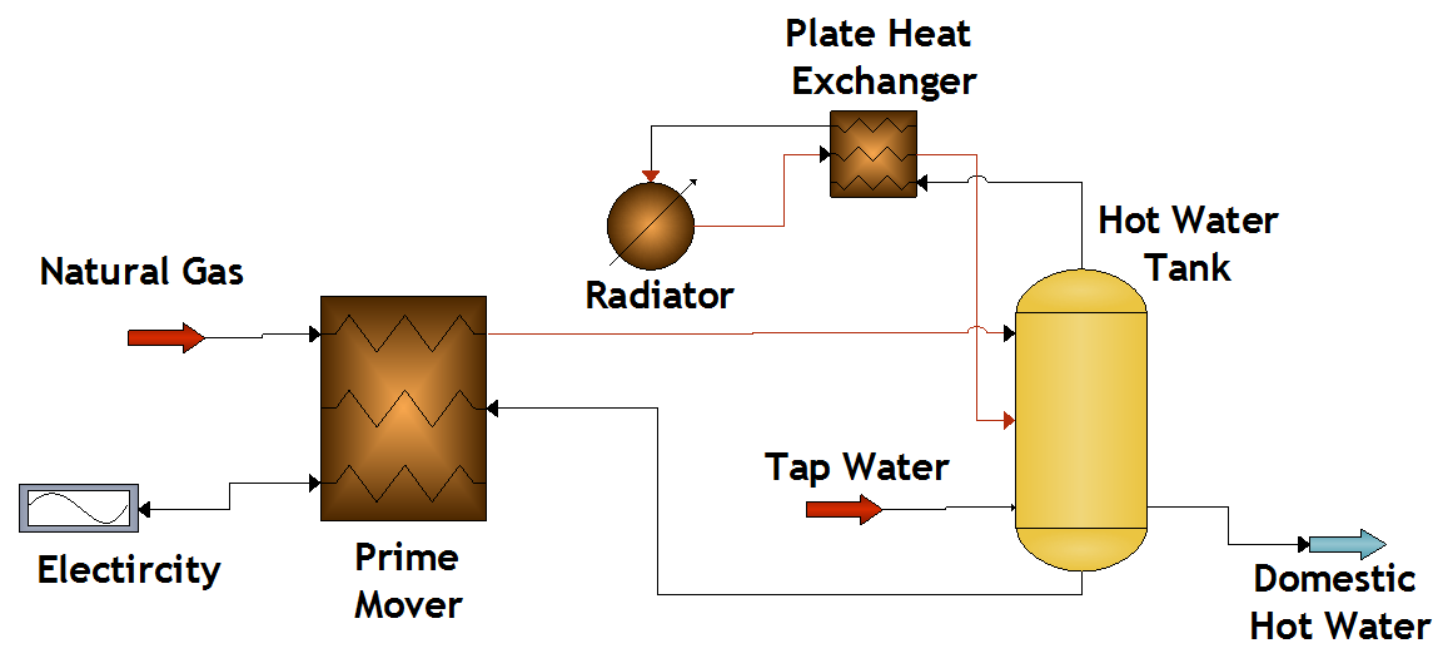

Figure 3. CHP system configuration used in the TRNSYS modeling of an NG fueled Otto engine. Integration of the PM in a $\mu \mathrm{CHP}$ configuration. 
One interesting aspect of this work was in the approach taken to model the transient behavior. It was accomplished via validating the PM with and without tank model, in addition to testing the real tank by itself to determine the nodes in the model. The research team also identified the PM's control strategy during this transient modeling. Integration of the validation experimental results with transient control strategy of the PM in both scenarios (with and without tank model) under different load profiles was conducted over a period of $160 \mathrm{~h}$ of simulation and compared with experimental results. Some minor discrepancies were identified due to: (i) The simulation not accounting for PM history, (ii) differences in stratification behavior, and (iii) standby losses. The authors concluded that the adopted modeling approach yielded $0.5-1.8 \%$ error in thermal and electrical outputs.

A broader review of the trigeneration systems and the gaps in global energy modeling approaches were discussed by $\mathrm{Gu}$ et al. [20]. The authors considered different PMs ranging from fuel cells, turbines, and ICE devices and highlighted the gaps in modeling approaches. Some of the key factors highlighted included: (i) Insufficient PM characterization data to represent the true performance of the trigeneration system, (ii) Lack of research efforts in to reliability assessment of the CCHP microgrid, and (iii) Uncertainties associated with energy management while interacting with renewable energy and the grid.

A research team from China studied an ICE-based $25 \mathrm{~kW}_{\mathrm{e}} \mu \mathrm{CHP}$ device considering overheat protection controls. This group focused on addressing the mismatch between energy demand and supply while optimizing the system design and operation/control strategy [21]. The authors developed a new model in TRNSYS software platform environment by implementing overheat protection control and status parameters of the exhaust gas. Overheat protection controls the temperature of the engine (primary circulation fluid) and cooling water (secondary circulation fluid) below the set point values. The unique aspect of this $\mu \mathrm{CHP}$ system was its ability to operate in manual, thermal priority, and electrical priority modes. A schematic of the experimental setup is shown in Figure 4 below.

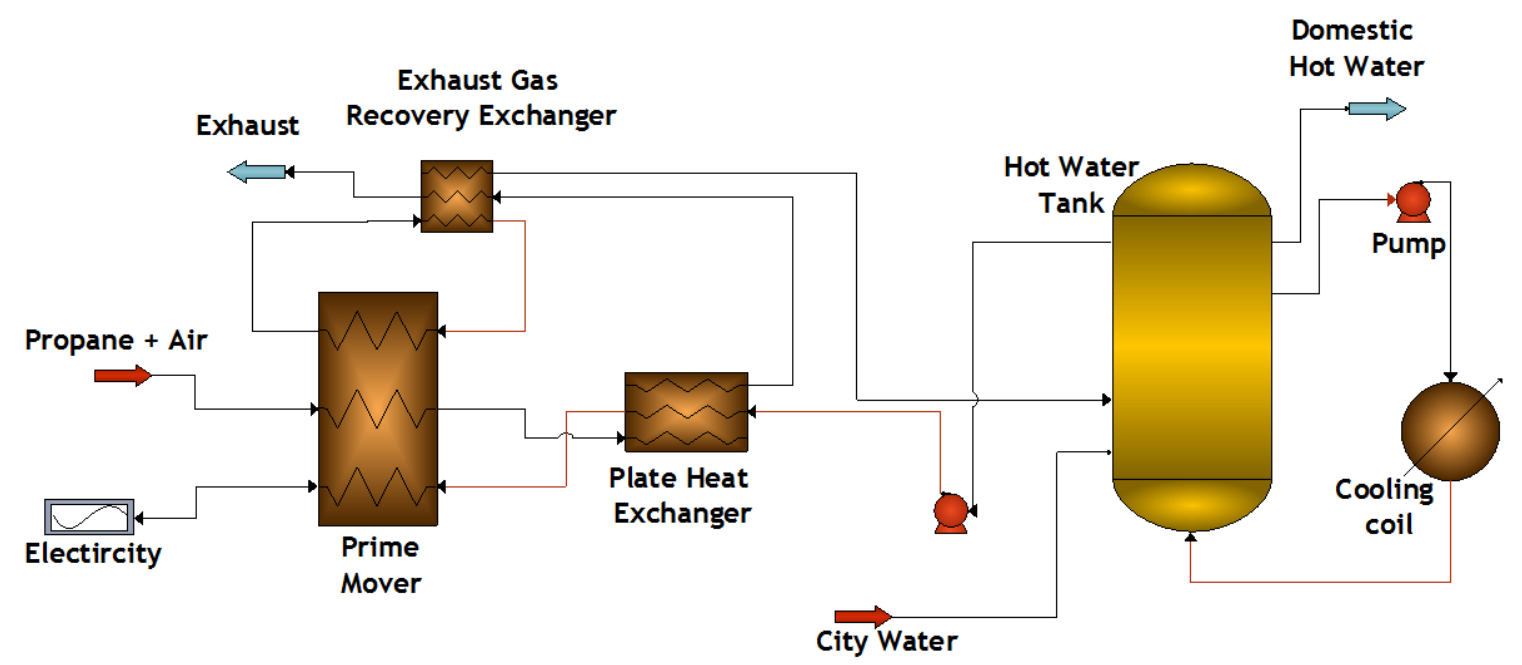

Figure 4. Experimental setup of a $25 \mathrm{~kW}_{\mathrm{e}} \mu \mathrm{CHP}$ system adopted by Zheng et al. for developing a new model in the TRNSYS platform.

The dynamic simulation model was based on the Annex 42 model but considered an additional control volume depicting the flue gas heat exchange and preventing overheating via a bypass loop across this control volume, as shown in Figure 5 below. Governing equations for all four control volumes were described in detail. The combustion control volume adopted the energy balance according to Equation (9) below, while the engine control volume utilized Equation (10), using similar nomenclature used in Equations (1)-(8). $Q_{\text {overheat }}$ is heat transfer from the engine control volume to the 
surroundings through the cooling radiator, while $\varepsilon_{\text {pro }}$ is the on $(1) / \mathrm{off}(0)$ state of the overheat protection control:

$$
\begin{aligned}
& m_{\text {flue }}\left(T_{\text {flue }, \text { out } 1}\right) C p_{\text {flue }}=Q_{\text {gross }}+H_{\text {fuel }}+H_{\text {air }}-Q_{\text {gen }}-E_{\text {gen }} \\
& {[M C]_{\text {eng }} \frac{d T_{\text {eng }}}{d \tau}=Q_{\text {gen }}-Q_{\text {jacket }, h x}-Q_{\text {skin, loss } 1}-Q_{\text {overheat }} \cdot \varepsilon_{\text {pro }}}
\end{aligned}
$$

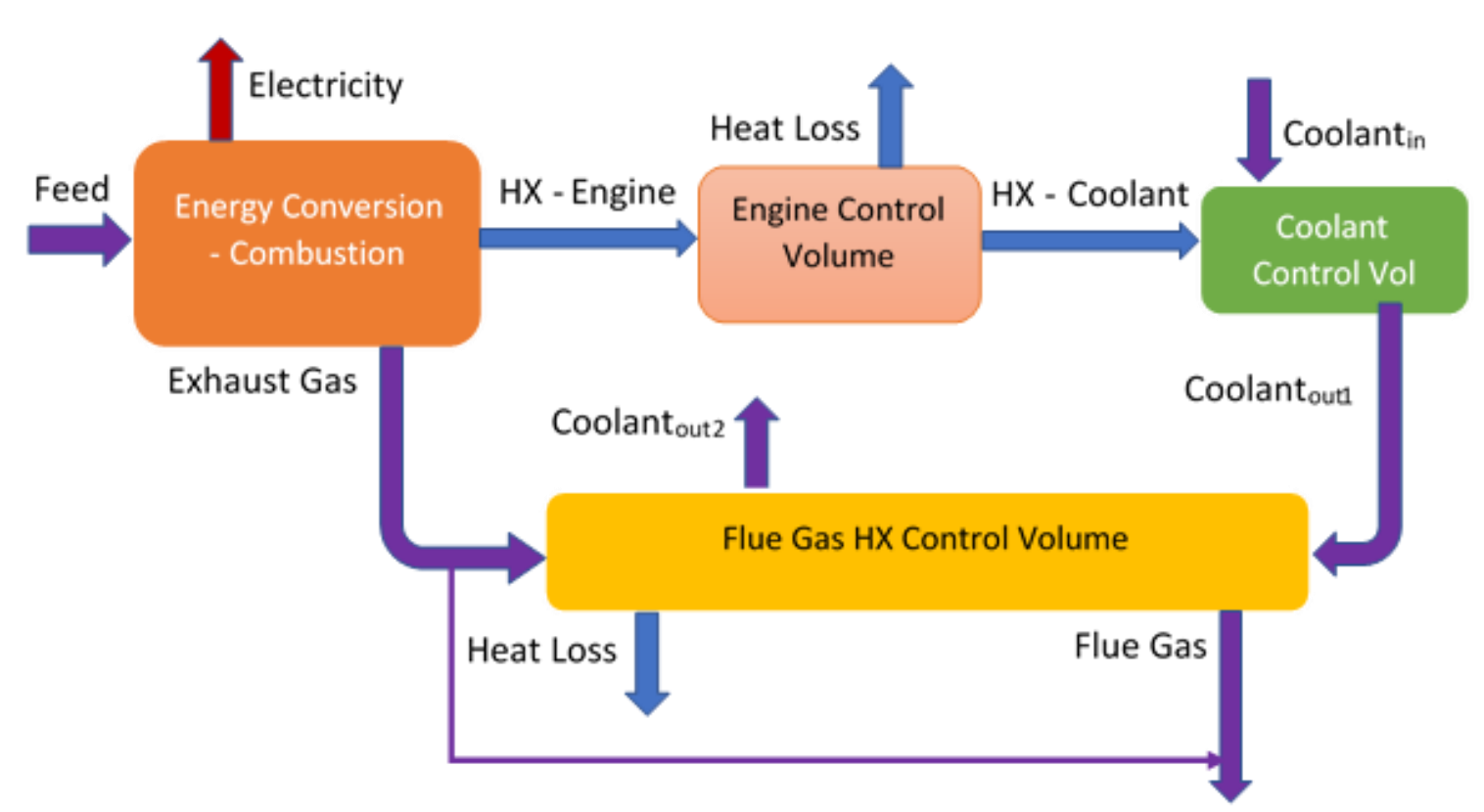

Figure 5. $\mu \mathrm{CHP}$ modeling approach with four different control volumes to address overheat protection.

Three categories of tests were conducted to analyze steady state, thermal priority and electrical priority modes of operation. At steady state, the heat exchange with the storage tank was completely bypassed and utilized direct cooling with blast fans. The other two modes utilized a valve, pump open/shut scheme to evaluate and control the onset of overheating temperature threshold. Different operational phases such as stand-by, startup, and cool-down, were also defined, as in the Annex 42 model. One significant difference in this particular model is the overheat protection control scheme where the governing logic and control coefficients for bypass, protection, and unit were defined.

Calibration of the parameters was accomplished by averaging the data over a $60-\mathrm{min}$ period during steady state operation. The warm-up and cool-down test approach was similar to the tests conducted by Rosato et al. [15]. Calibration of the dynamic temperature control scheme variables during the thermal priority mode was conducted by adjusting the thermal load manually (on/off, increase/decrease). Validation of the model was conducted via steady state and dynamic performance comparison with experimental data. The authors concluded that the dynamic simulation model can predict the performance to $\sim 98.5 \%$ of the observed value if the start-stop interval of the unit is $>30 \mathrm{~min}$, otherwise the predictability drops to $\sim 90 \%$.

Dynamic modeling of a megawatt scale CHP system was reported by a research group in Canada. The team developed a complete model using Thermolib and Simulink software (MathWorks, Natick, MA, USA) and validated it with system performance data from a real system. A 1.8 MWe natural gas fired lean burn gas combustion engine-based CHP system was utilized for the study [22]. The CHP system consisted of two stage heat recuperation and exchange to provide utility scale hot water and electricity while operating under a heat following strategy, in conjunction with a set of auxiliary boilers and thermal storage tanks. Underlying processes in each subsystem including the gas engine, heat recovery and thermal storage modules were simulated by applying the engineering principles of the combustion reaction, and mass and energy balances. Numerical data collected from the operational $\mathrm{CHP}$ power plant were used for validating the model. Thermal conductance of the heat recovery 
subsystem's heat exchanger was expressed according to Equation (11) and calculated based on the CHP plant performance data. Each subsystem's transient response for a $60-$ min period was utilized to simulate the dynamic behavior. The developed model predicted the CHP's thermal and electric outputs reliably:

$$
C=\frac{1}{\frac{\mathrm{A}}{A_{i} x_{i}}+\frac{A \ln \left(\frac{r_{o}}{r_{i}}\right)}{2 \Pi k L}+\frac{\mathrm{A}}{A_{0} x_{0}}}
$$

The performance of a standalone trigeneration/CCHP system was analyzed by Rey et al. using an internal combustion engine powered reversible heat pump coupled with thermal energy storage and heat exchangers. The simulation model was constructed using available library modules as well as customized models based on the experimental data of the real prototype [23], however, the authors did not provide the governing equations for critical subroutines including the engine and the energy storage. The model used equations relating the engine speed and heat pump state (on/off) with coolant heat transfer and fuel consumption. Several operating modes were analyzed at different engine speeds and the performance results were presented. The key contribution of this work was the methodology applied via testing, modeling and validation through simulation.

A simplified simulation tool was developed and presented for modeling the transient behavior of $\mu \mathrm{CHP}$ systems connected with thermal and electric storage units. The researchers unique approach involved integration of the control logic within the model, all developed around an ICE as PM, in Simulink software [24]. The model was divided in to six key modules: PM, thermal (TES) and electric energy storage (EES), heating (DHG) and electric grids (EG), and the user (u). One of the primary differentiating factors of this approach compared to other groups' work is the implementation of "time delay" in each subsystem allowing the estimation of both thermal and electric power during transients according to Equation (12):

$$
\frac{\partial P_{\text {out }}}{\partial t}=\frac{P_{\text {req }}-P_{\text {out }}}{\tau}
$$

This equation allowed the estimation of power output $\left(P_{\text {out }}\right)$ vs. power required $\left(P_{\text {req }}\right)$ under transient conditions. The delay time $\tau$ accounts for the step input response of a first-order linear time-invariant system, set at $\sim 63 \%$ of the final value. This approximation simplified the model for a very low computational time. The authors presented a detailed analysis of transient response of each component in a separate work [25]. The correlations between exhaust gas temperature, electric efficiency, and electric power output were adopted from previous work [26]. The architecture of the complete simulation model utilized in this work is shown in Figure 6. One of the key differentiating factors of this model was integration of the thermal energy storage (TES) module represented by Equation (13) and electric energy storage (EES) module represented by Equation (14):

$$
\begin{aligned}
& \mathrm{E}(t)=\int_{0}^{E_{T E S, \max }}\left[\left(P_{t h, P M, \text { out }}-P_{t h, P M, \text { in }}\right)-P_{\text {th,TES,out }, \text { ref }}\right] d t \\
& \mathrm{E}(t)=\int_{0}^{E_{E E S, \max }}\left[\left(P_{e l, P M, \text { out }}-P_{e l, P M, \text { in }}\right)-P_{e l, E E S, \text { out }, \text { ref }}\right] d t
\end{aligned}
$$




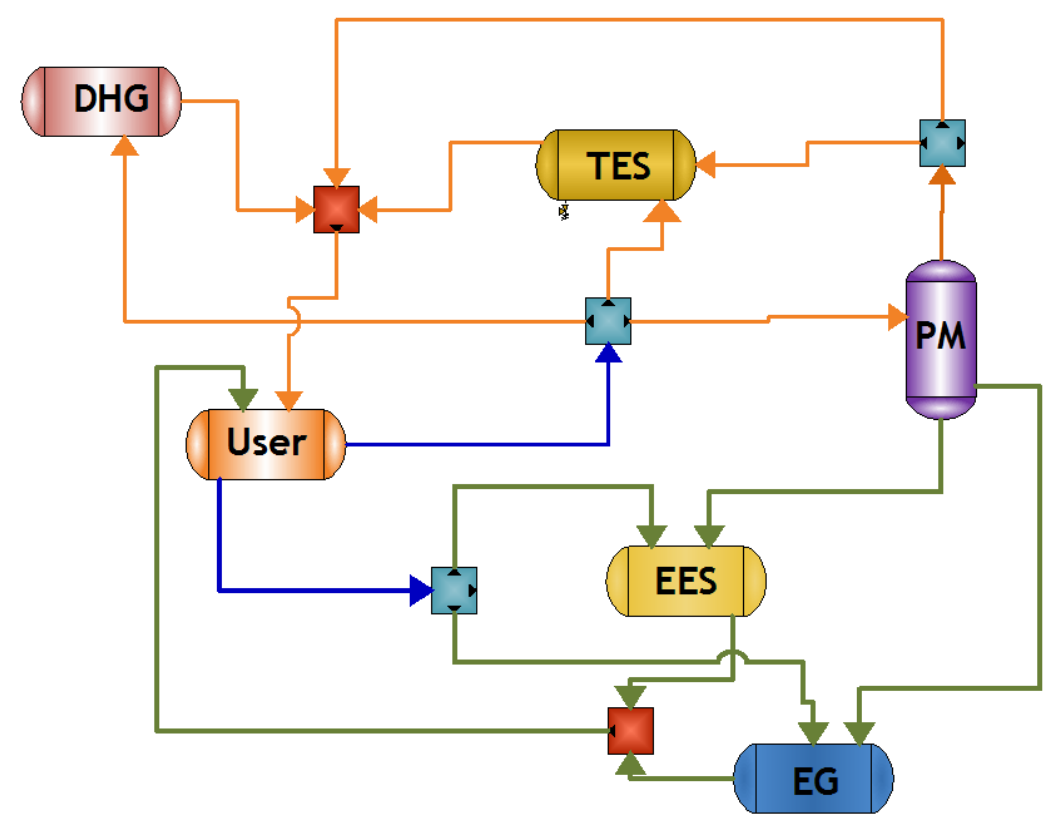

Figure 6. Simulation architecture used in transient operation model developed by Ippolito F., and Venturini M. DHG-District heating grid, EG-Electric grid, EES-Electric energy storage, TES-Thermal energy storage, PM-Primary mover. Green line represents electric power flow, Orange line represents thermal power flow. Blue lines represent corresponding electrical thermal requirements from the user.

The energy stored in the corresponding energy storage module (TES/EES) was modeled utilizing thermal/electrical power from the PM $\left(\left(P_{t h / e l, P M, o u t}-P_{t h / e l, P M, i n}\right)\right.$, and the thermal/electric power required to the TES $\left(P_{e l / t h, E E S / T E S, \text { out,ref }}\right)$. The model however did not account for the round-trip efficiency. Governing equations for all other sub-systems along with the control logic were presented in detail. Using this novel approach, dynamic effects are accounted for in a simplified way by the simulation model. Also, the behavior at steady-state conditions was analyzed by identifying all energy fluxes. Another significant outcome of this work is the control logic setup allowing the optimization of thermal and electric energy outputs. The authors further extended their work [27] by utilizing the developed model in a transient environment to evaluate the relative deviation between steady state model instead of a dynamic model. The deviation was estimated as $\sim 6 \%$ which can become a significant energy penalty when considered over long duration of time, demonstrating the impact of transient considerations on the overall reliability.

Given the significance of thermal energy storage in the reliability of the simulation model environment, Campos Celador et al. developed thermal storage tank models to analyze the influence of modeling strategy on the energy balance, its integration in the $\mu \mathrm{CHP}$ scheme and the reliability of the global model [28]. A general approach in some of the $\mu \mathrm{CHP}$ modeling efforts considers only the energy flow, neglecting the different temperature levels. The authors defined three different levels of stratification viz. actual stratification model, ideal stratified water tank model, and fully mixed water tank model. It was noted that in ICE-based CHP plants, the water in the tank shows an intermediate temperature profile between the ideal stratified case and the perfectly mixed case, influenced by tank design and CHP operation, and ultimately impacting the dynamic operation of the plant. These three approaches were modeled in TRNSYS using one dimensional convection equation and transforming it into a temperature dependent equation. The modeling equations were presented in detail along with the cogeneration plant scheme and its equipment. The authors concluded that the modeling approach did not influence the energy and exergy efficiency of the $\mu \mathrm{CHP}$ plant significantly, however differences in economic feasibility of the three tank modeling approaches were identified.

The influence of accounting for transient losses across the thermal storage device has been discussed and presented in a work performed by Thomas et al. [29]. This work utilized the DIN 4709 
standard (Directive 2004/8/EC of the European Parliament and of the Council on the promotion of cogeneration) for evaluating the $\mu \mathrm{CHP}$ units, based on a 24-h test procedure providing a variable thermal load. This study showed how the new standard identified a 3-6\% performance loss in the thermal efficiency, compared to the steady state approach.

Time domain modelling and dynamic analysis of CHP connected to the power grid was performed by Xie et al. [30]. Based on the mass and energy balance, this paper analyzed the principles and dynamic characteristics of the main CHP components, including gas internal combustion engine, synchronous generator, waste heat exchanger, water storage tank, exhaust-heat boiler, and gas fired boiler. Non-linear time-domain models for each subcomponent in the CHP system was built using input and output parameters. The simulation method coupled all individual component models with different time constants. The work in this paper can provide a theoretical basis for modelling, joint scheduling, management, and development of various energies.

A recent study focused on biomass fueled $30-100 \mathrm{~kW}$ scale mini-CHP via mathematical modeling [31], for applications in cold climates. The authors conducted this preliminary study in order to estimate energy transfer related parameters to aid in identifying individual component specification. The power plant consisted of a gasifier followed by a chain of heat exchangers for water heating as well as engine air preheating and subsequent supply of the syngas in to the engine. This study assumed three separate control volumes with energy flow between the fuel processor, heat exchangers and the engine while relating variables to performance equations after utilizing thermodynamic databases for fluid properties.

A hybrid power engine-heat pump (HPGHP) system was shown to provide $12 \%$ higher efficiency compared to an engine driven heat pump when operated as a trigeneration unit [32]. This paper mainly discussed the steady-state performance of the HPGHP system under different loads of the compressor and focused on the establishment of a steady state model of the engine. The hybrid configuration consisted of a $12.5 \mathrm{~kW}$ gas engine, a motor connected coaxially with the engine, Lithium ion based electrical energy storage, and the heat pump. The engine was modeled through a correlation between thermal efficiency, torque, and speed via a curved surface equation while the electrical model accounted for state of charge (SOC) and state of health of the battery (SOH). The model of engine waste heat recovery was simplified by assuming that the recovery coefficient is a single valued function of engine's waste heat, established by fitting experimental data. This coefficient was calculated by Equation (15), where $B$ is the mass flow rate of gas $(\mathrm{kg} / \mathrm{s}), R$ is the calorific value of the gas, $\mathrm{kJ} / \mathrm{kg}, Q$ is the energy supply to the compressor, $\sigma$ is the engine waste heat recovery coefficient, $\eta_{e}$ is the thermal efficiency:

$$
Q_{y}=\sigma\left(1-\eta_{e}\right) Q=B R \sigma\left(1-\eta_{e}\right)
$$

The control strategy adopted real time adjustments of the drive system operating conditions, standing on the engine optimal torque curve combined with SOC. The developed model predicted the SOC and $\mathrm{SOH}$ of the battery module accurately under both heating and cooling load scenarios. The key takeaway from this study is the model configuration including the SOC and $\mathrm{SOH}$ of the battery while coupling power distribution between the gas engine and the motor.

A hybrid ICE-Organic Rankine Cycle (ORC) CHP system was integrated and studied in detail through whole system optimization framework. The authors considered design and operation of both the ICE PM and secondary ORC engine simultaneously within the combined system to optimize the overall system performance. The dynamic ICE model was combined with steady-state model of the ORC for optimizing peak power and peak efficiency [33]. Thermodynamic model of the ICE system was accomplished with a detailed set of ordinary differential equations (ODEs) by assuming: (1) each engine cylinder was modelled as open control volume with fuel intake and exhaust gases, (2) heat addition to the engine cylinder was modelled using the Wiebe function (Equation (16)), (3) heat transfer to the cooling water was modelled using Woschini's instantaneous heat transfer (correlation (Equation (17)) 
and radiation heat losses were model via Annand's correlation (Equation (18)). Conservation laws were applied for modeling heat transfer losses and represented by ODEs:

$$
\begin{gathered}
\frac{d x_{b}}{d \vartheta}=\frac{n \alpha}{\vartheta_{d}}\left\{1-\left[1-\exp \left(-\alpha\left\langle\frac{\vartheta-\vartheta_{i g n}}{\vartheta_{d}}\right\rangle\right)\right]\right\}\left[\frac{\vartheta-\vartheta_{i g n}}{\vartheta_{d}}\right]^{n-1} \\
h_{g}(\vartheta)=3.26 P(\vartheta)^{0.8} U_{p}(\vartheta)^{-0.8} b^{-0.2}\left(\frac{P(\vartheta) V(\vartheta)}{m(\vartheta) R}\right)^{-0.55}
\end{gathered}
$$

where $\vartheta_{\text {ign }}$ is the ignition angle, $\vartheta_{d}$ is combustion duration time, $\vartheta$ is the crankshaft angle, $\alpha$ was assumed to be 5 and $n=3$. Instantaneous characteristic gas velocity was represented by the term $U_{p}(\vartheta)$, $P$ is the pressure, $b$ is the cylinder bore diameter, $m$ is the mass flow rate, and $R$ is the gas constant:

$$
h c=\alpha \frac{k_{g}}{B} R_{e}^{0.7}+b \frac{\left(T_{g}{ }^{4}-T_{w}{ }^{4}\right)}{\left(T_{g}-T_{w}\right)}
$$

where $h c$ is the spatial average heat transfer coefficient, $k_{g}$ is thermal conductivity coefficient, $B$ is piston bore, $R e$ is the Reynolds number, $b$ is Annand constant, $T_{g}$ is the zonal temperature, and $T_{w}$ is the wall temperature. Twenty one ODEs representing the complete ICE system's thermodynamic model were solved in MATLAB using the non-stiff ODE solvers ode113 and ode45. This model was later successfully validated using specification sheets for natural gas fueled CHP-ICE modules. The optimal integrated ICE-ORC CHP system was later shown to achieve up to $30 \%$ higher power output than a nominal ICE based configuration. This study also looked at different CHP capacities and concluded that the heat recovery factor was more favorable in medium-sized engines. This study provided a very broad overview of the modeling approach and its impact on system performance. It also provides very useful insights in to modeling considerations and their impact on hybrid systems involving waste heat recovery utilization.

A techno-environmental model was also reported where ICE PMs fueled by biogas were shown to achieve economic and environmental benefits while the influence of different sensitivity parameters was presented [34-36].

Analysis and modeling of a residential micro-multi-generation system were developed from the energy efficiency and economic assessment viewpoints [37]. The analysis was conducted on a complete energy system consisting of a natural gas fueled ICE CHP supported by renewable photovoltaic plant, a backup boiler, a thermal energy storage and an electrical energy storage module. This study is unique as it accounted for both thermal and electrical energy storage for optimal performance, unlike most of the previous studies involving just the thermal storage. Thermal storage was considered in the model (Equation (19)) in order to decouple the heat production from the demand:

$$
C \frac{d T_{w}}{d T}=P_{t h, b o i l}+P_{t h, C H P}-P_{t h, u s}-U \cdot S \cdot\left(T_{w}-T_{a}\right)
$$

where $C$ is the thermal capacity of the water inside the tank, $P_{t h, b o i l}$ is the thermal power provided by the boiler, $P_{t h, \mathrm{CHP}}$ is the thermal power provided by the CHP, $P_{t h, u s}$ is the thermal power required by the user, $U$ and $S$ are thermal transmittance and surface area of the tank while $T$ is the temperature.

A recent study summarized the basic theoretical and practical concepts necessary to simulate and optimize the design and operation of fleet of energy units of different configurations [38]. Particularly, the paper presented variables and equations that are required to simulate the dynamic behavior of the system, the operational constraints, and a suitable objective function. This paper serves as a guide for researchers looking in to modeling CHP systems as it clearly demonstrates how to build the dynamic model and frame an optimization problem. Essentially, this paper provides a general approach/recipe to choose the CHP configuration to optimally utilize the available energy resources. The dynamic modeling approach is based on Mixed-Integer Non Linear Programming (MINLP). The generic model 
was developed via hybrid black box-control volume approach where the energy devices with input and output flows were combined with different energy transfer modes between the devices and with the environment. The MINLP approach was applied using binary variables to represent on/off status while the mass and energy balances were related through equations of state. Characteristic maps represent the units linking fuel to its products. Power and energy amounts were considered in the model using variables $\varphi$ and $\Phi$ respectively, which depend on intensive and extensive quantities (such as pressures, temperatures, mass flow rates, fluid properties etc.). The energy balance equations of the general energy system included interconnections between energy devices, energy conservation within these devices and finally their interaction with external environment. Energy conservation assumed generic differential form shown in Equation (20) while the behavior of the energy storage unit was represented via Equation (21):

$$
\begin{gathered}
\frac{d \Phi_{j}(t)}{d t}=\sum_{p} \varphi_{j, \text { in }}(t)-\sum_{q} \varphi_{j, o u t_{q}}(t)-\varphi_{j, L}(t) \\
\Phi_{j}(\tau)=\Phi_{j}(0)+\int_{t=0}^{\tau} \sum_{p} \varphi_{j, i n_{p}}(t) \cdot d t-\int_{t=0}^{\tau} \sum_{q} \varphi_{j, o u t_{q}}(t) \cdot d t-\int_{t=0}^{\tau} \varphi_{j, L}(t) \cdot d t
\end{gathered}
$$

The symbol $(t)$ means that the value of the variable is a function of time. The numerical subscripts $(1,2$, etc.) identify the number of the device and the subscripts in, out, and $L$ refer to the flows of fuel, product, and loss/emissions, respectively. $\Phi_{j}(0)$ is the initial value of the energy contained in the storage unit, and $\Phi_{j, i n}, \Phi_{j, o u t}$, and $\Phi_{j, L}$ are the total amount of energy sent to, taken from and lost by the storage unit in the time period 0 to $\tau$, respectively. The author then demonstrated the application of the proposed guidelines of the generic model to develop an optimum design and operation of a set of devices serving the thermal and electrical loads of the user via a hybrid PV configuration in a district heating network. Additionally, system design optimization and energy storage optimization was also presented in detail by considering linear characteristic maps of the energy conversion units and applying linearization technique to the nonlinear constraints.

The potential utilization of biomass for generating syngas and subsequent utilization in a reciprocating engine based micro-cogeneration system was reported [39]. Entire $20 \mathrm{~kW}_{\mathrm{el}}$ microcogeneration plant was modeled by utilizing all waste heat streams in the gasification processes ranging from feed drying to syngas generation. The interactions between different unit operations were modeled, optimized, and validated. A comprehensive thermodynamic model was developed using Thermoflex ${ }^{\mathrm{TM}}$ (Thermoflow Inc., Florida, USA) and GT-Suite ${ }^{\circledR}$ (Gamma Technologies, LLC, Illinois, USA) software tools for modeling the gasifier and the engine respectively. GT-Suite ${ }^{\circledR}$ is a one-dimensional simulation tool for evaluating concepts and detailed systems analysis and optimization of diverse chemical and mechanical systems. The optimization process was done using modeFRONTIER ${ }^{\circledR}$ (ESTECO SpA, Trieste, Italy) software package. The authors presented favorable operating conditions for a balanced system operation with further recommendations for optimal design configuration. Similarly, Chang et al. utilized the Thermoflex ${ }^{\mathrm{TM}}$ and GT-Power platforms (Gamma Technologies, LLC, Illinois, USA) to model a rice husk-based biomass fueled ICE CHP system. The authors showed the influence of gas composition on overall efficiency by modifying the 1D numerical model representing the engine.

Yang et al. recently presented a hybrid engine-heat pump system and its control strategy and optimization [40]. The reported system consisted of a primary drive along with heat recovery and heat pump sub systems. Multiple linear regression theory and least square methods were adopted to develop the correlation between thermal efficiency and engine torque. Instantaneous optimization control strategy while considering SOC of the battery, similar to the approach discussed in [32] was employed in this study. Based on their analysis, the authors identified optimal ranges of compressor speeds for different modes of operation. 
Performance assessment of a combined heating and cooling power plant (CHCP) based on a $15 \mathrm{~kW}$ internal combustion engine was investigated through 1-D thermo-fluid dynamic characterization [41]. The key focus in this study was the optimal sizing of the poly-generation plant and a flexible waste heat recovery system (WHRS), delivering thermal power at different temperature levels using a $15 \mathrm{~kW}$ scale compression ignition engine fueled by liquified propane gas. This study adopted a unique configuration where the entire micro-CHP was housed inside an insulated container. Heat recovery was accomplished via three different heat exchangers viz. (i) radiative heat recovery, (ii) coolant stream heat recovery, and (iii) exhaust gas heat recovery, as shown in Figure 7. The engine was modeled via one-dimensional approach for intake and exhaust pipes and zero-dimensional approach for the cylinders. Equations representing the continuity, momentum, and energy aspects of the 0D/1D approach were detailed. The primary numerical model of the CHP was utilized to analyze the performance of a more flexible WHRS. In this case, two separate circuits were employed to yield different thermal outputs. The radiative and coolant heat exchangers were combined while the exhaust heat recovery was kept separate, providing the thermal quality flexibility. Additionally, the trigeneration system was also modeled using an absorption chiller.

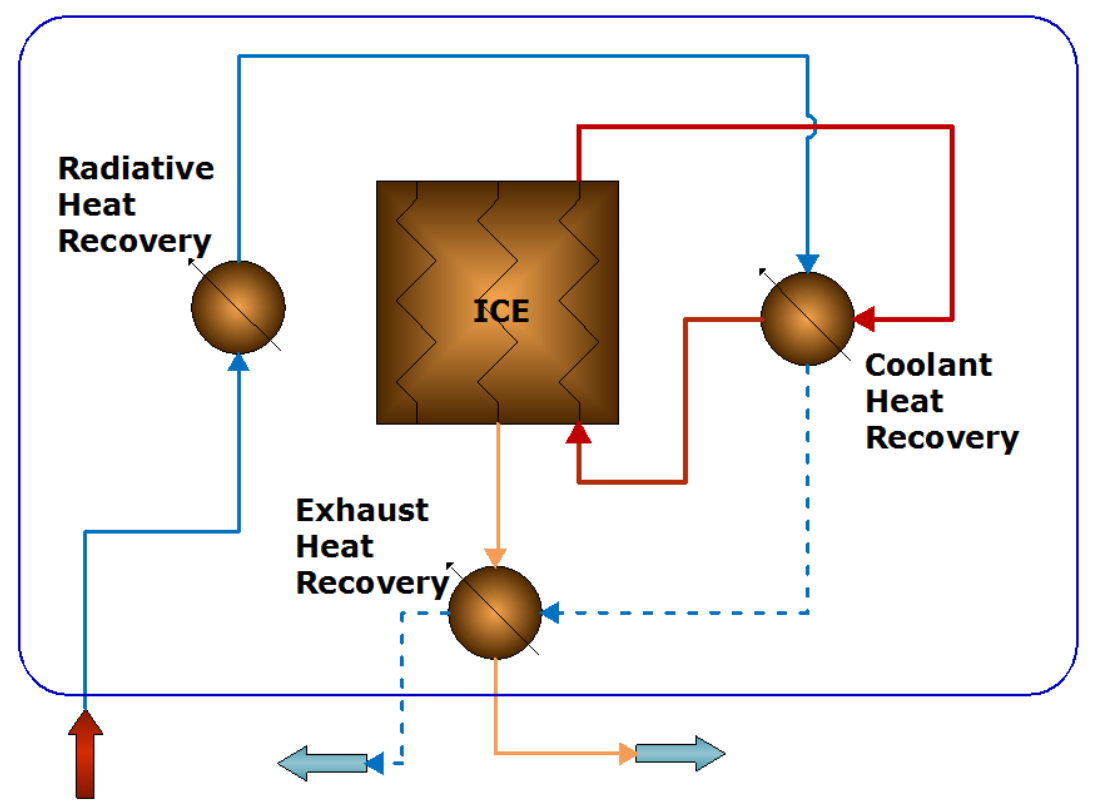

Figure 7. Micro-CHP plant with integrated heat exchangers for dual thermal output.

A multi-source integrated CHP system consisting of a biodiesel fueled ICE tied with ORC bottoming cycle along with renewable PV and wind turbine for supporting thermal and electrical loads of a commercial center was presented [42]. The authors utilized a thermodynamic model representing the hybrid ICE-ORC system. A steady state condition was utilized in the model while the pressure drops and heat losses were completely disregarded in this $100 \mathrm{~kW}_{\mathrm{el}}$ system. The authors however did not discuss their model calibration and validation methods.

Application of a $4 \mathrm{~kW}$ Otto cycle engine for meeting the energy needs of a residential building was studied by Jung et al. [43]. The authors utilized TRNSYS software package for developing the simulation model to operate the CHP in thermal load following mode. The CHP model was combined with a stratified tank via a plate heat exchanger after recovering the heat from engine cooling jacket, oil coolant, exhaust gas and the generator, similar to the configuration shown in Figure 7. Calibration of the TRNSYS ICE module was carried out using experimental data from both steady state and transient state measurements. The error in fuel use and electrical output was negligible and the thermal output error was reported as $1.7 \%$. Standalone stratified tank calibration and validation was carried out with 
experimental results. This study also observed a peak error of $4.8 \%$ without tank model and $7.4 \%$ with tank model, between experimental and simulation predictions.

A district heating network (DHN) system's control and optimization strategy was presented in [44]. This study did not utilize any PM but rather managed the available energy to optimize thermal utilization in a distributed network. The authors constructed a scaled-down version of the DHN to benchmark advanced control algorithms by studying the thermal and hydraulic characteristics of the original system. Details regarding the experimental setup and simulation considerations in this study are relevant to the present review as it provides insights in to thermal load management in a $\mathrm{CHP}$ configuration and provides a methodological approach in studying the thermal behavior of any system. The thermal mass was represented by immersing the copper pipe carrying the thermal energy in an acrylic water tank, representing the relevant heat transfer of the actual system. Uniform thermal distribution was achieved by adding an impeller to the tank. A Peltier junction was added to the outside of the tank to mimic heat loss to the ambient. Mathematical representation of the temperature dynamic in the thermal mass was accomplished via nonlinear first-order system while applying the energy conservation law, shown in Equation (22). Where $c_{v}$ is the specific heat of water, $V$ is the volume of thermal mass, $\rho$ is the density of water, $T_{T M}$ is the thermal mass temperature, $Q_{\text {pelt }}$ is the rate of heat rejection through the Peltier. $Q_{i n}$ is the heat flux from the copper pipe (Equation (23)) and $Q_{a m b}$ is the thermal loss to environment (Equation (24)), $\mathrm{h}$ is the convection heat transfer coefficient, $m_{T M}$ is the mass flow rate of the hot water through copper pipe, As is the convection surface area, $T_{\text {in }}$ and $T_{\text {out }}$ are the temperature of the water at the inlet and outlet of the copper pipe, the subscript $t$ indicates the tank thermal mass, while subscript $C$ refers to the copper pipe:

$$
\begin{gathered}
c_{v} V \rho \frac{d T_{T M}(t)}{d t}=\dot{Q}_{i n}-\dot{Q}_{a m b}-\dot{Q}_{p e l t} \\
\dot{Q}_{i n}=h_{c}\left(\dot{m}_{T M}\right) A_{S, C}\left(\frac{T_{\text {in }}-T_{\text {out }}}{2}-T_{T M}\right) \\
\dot{Q}_{a m b}=h_{t} A_{S, t}\left(T_{T M}-T_{a m b}\right)
\end{gathered}
$$

The model was further expanded with rest of the equations representing the pressure losses, flow velocity, and ambient thermal losses and implemented in MATLAB/Simulink, followed by individual component calibration for each thermal mass. Validation experiments revealed $<1 \%$ error in temperature predictions.

Modeling of a CHP system with a downdraft gasifier consuming biomass and providing electrical and thermal energy from a $300 \mathrm{~kW}_{\mathrm{e}}$ ICE-based system was studied [45]. This study developed a model, based on thermodynamic equilibrium calculations in Engineering Equation Solver (EES), was later validated using values from the open literature. Exhaust gas stream from the ICE was utilized in treating the biomass feed for optimizing the size and overall system efficiency.

A study focusing on modeling a hybrid internal and external combustion engine-based CHP was recently reported [46]. Variable power output and exhaust gas from the internal combustion engine was utilized for operating a stirling engine, both modeled using the same approach of zero-dimensional model reported above. A thorough detail of the mathematical model along with equations representing the instantaneous temperature and pressure rate of IC engine, rate of total thermal loss, recoverable thermal loss, non-recoverable thermal loss to surrounding, convective and radiative heat transfer coefficient, and heat output in various parts of the system were presented. For the case of micro-CHP, the key governing equations of interest, representing the thermal availability are provided below:

$$
\begin{gathered}
\frac{d Q_{t}}{d \theta}=\frac{d Q_{r e c}}{d \theta}+\frac{d Q_{\text {non-rec }}}{d \theta} \\
\frac{d Q_{r e c}}{d \theta}=\frac{d Q_{e x}}{d \theta}+\frac{d Q_{\text {cool }}}{d \theta}
\end{gathered}
$$




$$
\frac{d Q_{n o n-r e c}}{d \theta}=\frac{d Q_{\text {loss }}}{d \theta}
$$

$\frac{d Q_{e x}}{d \theta}, \frac{d Q_{\text {cool }}}{d \theta}, \frac{d Q_{\text {loss }}}{d \theta}$ represent rate of recoverable thermal loss from exhaust, cooling system and non-recoverable thermal loss to surrounding, respectively. Annand heat transfer model was used to calculate the heat transfer between cylinder wall and gas, as shown in Equation (28), the convective heat transfer coefficient $\left(h_{c}\right)$ according Equation (29), and radiative heat transfer coefficient $\left(h_{r}\right)$ according to Equation (30):

$$
\begin{aligned}
\frac{d Q_{\text {cool }}}{d \theta} & =\left(h_{c}+h_{r}\right) A\left(T-T_{w}\right)\left(\frac{1}{\omega}\right) \\
h_{c} & =b\left(\frac{\rho_{g a s} u_{p} B}{\mu_{g a s}}\right)^{0.7} \frac{k_{g a s}}{B} \\
h_{r} & =4.25 e^{-9}\left(\frac{T^{4}-T_{w}^{4}}{T-T_{w}}\right)
\end{aligned}
$$

where $A, T_{w}, \omega$ represent area of heat transfer, cylinder wall temperature, and average speed of gas at cylinder, respectively. Also, $k_{g a s}, \rho_{g a s}, B$ and $\mu_{g a s}$ are piston speed, gas thermal conductivity, cylinder bore and gas dynamic viscosity, respectively. Together, these governing equations predicted the rate of heat output in various components of the IC engine. Stirling engine modeling was conducted using a set of differential equations. The key differentiating factor in this modeling approach was the simplicity and calculation speed without needing combustion details. The zero-dimensional models are divided into different zones, similar to the control volume approach used in majority of the previous models but using double-Wiebe function to predict the unburnt fuel mass. The authors also laid out a flow chart of the CHP modeling approach where the first step involves technical specifications of the engine along with initial conditions of the IC for the zero-dimensional model. The next step involves utilizing the evaluated temperature and heat output of exhaust gases for the heater of the stirling engine. A combined analysis of both engines predicted complete technical, economic, and environmental value of the CHP.

Application of artificial neural network (ANN) model for simulating a dual fuel internal combustion engine fueled by biogas and diesel fuels, at a $3.5 \mathrm{~kW}$ capacity was recently reported. The authors developed a novel ANN model of the engine while utilizing biogas as the primary fuel, generated from batch scale biogas digesters [47]. The ANN model was designed to estimate fuel and air flow rates along with exhaust gas temperature while considering the key input layer parameters of engine power, fuel flow rate and methane content of the biogas feed. The models were validated using two criteria, minimization of root mean square error (RMSE, Equation (31)) and the value of R-squared, representing the absolute and relative measure of fit, respectively:

$$
\text { RMSE }=\sqrt{\sum_{i=1}^{n}\left(\text { Output }_{\text {Cal }}-\text { Output }_{\text {Mes }_{i}}\right)^{2} / n}
$$

Output $_{\text {Cali }}$ and Output $t_{\text {Mesi }}$ are respectively the $i^{\text {th }}$ calculated and measured output values and $n$ is the total number of measured output data. The ANN-based model was shown to provide reliable engine performance parameters of electrical and thermal outputs however the integration of the engine with a true micro-CHP model including the intermediate heat exchanger for thermal utilization was not carried out. 
A novel methodology was recently proposed for designing and modeling polygeneration systems by combining pinch analysis, mathematical programming, and heat/mass flows in the energy processing system [48]. The complexity of polygeneration systems is high compared to simple CHP systems as there are numerous energy providers and consumers with different thermal quantities and qualities. The methodology combines pinch analysis via problem table algorithm with Mixed Integer Linear Programming (MILP) while characterizing thermal energy flow between different system components and allowing flexibility to exchange heat energy in different temperature intervals. This study utilized Open Problem Table (OPT) approach where the energy suppliers and consumers were connected with virtual heat exchanger network where physical and structural constraints were imposed in synthesis and design optimization problems. The study detailed the OPT structure in a detailed fashion where heat cascade from hot to cold systems while balancing the heat in a temperature interval was represented by a set of equations. The authors considered information from the data sheet of a commercial $6 \mathrm{MW}$ gas engine and setup the problem table specifically considering all four primary heat sources and corresponding thermal properties viz, engine exhaust (ieg), cooling water (ijw), lubricating oil (ilo), and charge air (iac), a generalized version of which is shown in Table 2 below, where hot flow i present in time $\mathrm{k}$ is represented for individual hot sources, $\mathrm{m}$ is the mass flow rate. This table represents potential cogenerated heat supplied by the hot flows in each temperature interval along with that of cold flows $(j)$ in the same temperature interval, shown as energy for central heating (jas) and saturated steam in a boiler (jad). $Q O$ and $Q D$ represent heat supplied by the hot flow $i$ and heat consumed by the cold flow $j$, respectively.

Table 2. Problem table of the engine's heat production.

\begin{tabular}{|c|c|c|c|c|c|c|c|}
\hline Temperature, $T$ & Interval k & QO(ieg) & QO(iac) & QO(ijw) & QO(ilo) & $\mathrm{QD}(\mathrm{jas})$ & QD(jad) \\
\hline$X \operatorname{deg} C$ & 1 & & & & & & \\
\hline$Y \operatorname{deg} C$ & 2 & & & & & & \\
\hline . & . & & & & & & \\
\hline . & . & & & & & & \\
\hline$\cdot$ & $\cdot$ & & & & & & \\
\hline $25 \operatorname{deg} C$ & $\dot{\mathrm{k}}$ & & & & & & \\
\hline
\end{tabular}

The optimization model was composed of decision variables representing: technologies and their sizes $(\mathrm{kW})$, operational loads in each time period, energy resources (e.g., grid electricity, fuel), heat supply and demand in each temperature interval, and heat surplus from one temperature interval to the next (heat cascade). The technical and economic feasibility of installing various types of technologies, including gas engine, gas boilers, single and double-effect absorption chillers, and mechanical chillers, was assessed using the MILP model in the LINGO software package, demonstrating optimal energy utilization for a hospital building energy application.

Olympios et al. applied a new design based on multi-objective real-time operation control of a CHP system [49]. Stochastic optimization technique considering risk within the optimization problem was presented for practical application of CHP systems. For model simplification purposes, this work considered three linear relationships between fuel input, heat output and electrical output at different loads on the engine as the key focus was to reduce risk to help size the CHP's engine appropriately.

Chen et al. reported a hybrid $100 \mathrm{~kW}_{\mathrm{e}} \mathrm{ICE}$-Geothermal heat pump system optimized for specific building applications via multi-criteria method based on energy, economic and environmental factors [50]. Conservation laws were applied for energy balancing while a simple correlation relating efficiency $\left(\eta_{E L}\right)$ to electric power $\left(E_{I C E}\right)$, shown in Equation (32). The waste heat output of the exhaust gas $\left(Q_{e x}\right)$ and coolant $\left(Q_{j w}\right)$ were determined via polynomial fitting curves, shown in Equations (33) and (34), where $b$ and $c$ constants and $P L R_{I C E}$ is the part load ratio: 


$$
\begin{gathered}
\eta_{E L}=28.08\left(E_{I C E}\right)^{0.0563} \\
Q_{j w}=\left(b_{1} P L R_{I C E}^{2}+b_{2} P L R_{I C E}+b_{3}\right) E_{I C E} \\
Q_{e x}=\left(c_{1} P L R_{I C E}^{2}+c_{2} P L R_{I C E}+c_{3}\right) E_{I C E}
\end{gathered}
$$

The authors utilized data sets of commercial engines for the electrical efficiency, and compared jacket water and exhaust gas factors calculated from the above equations with ASHRAE's statistical data set and reported RMS errors of $<2 \%$.

A multi-scale framework for the capturing the variations in the performance and cost of CHP systems and heat pumps with scale (size, rating) and operating conditions using data-driven models based on an extensive analysis of commercial products was presented [51]. The authors studied several commercial ICE-CHP products' thermal and electrical efficiencies in the range of $1 \mathrm{~kW}_{\mathrm{e}}$ to $9 \mathrm{MW}_{\mathrm{e}}$, and notied that the electrical efficiency drops by $\sim 5 \%$ while thermal efficiency increases by $5 \%$ when an engine is operated at $50 \%$ of the rated power. This study proposed two simple two-layer feed-forward neural network fits to predict the average performance between $50 \%$ to $100 \%$ part-load levels. The networks were trained using Levenberg-Marquardt back propagation algorithm and 10 hidden neurons. $70 \%$ of the data points were used for training, and $15 \%$ each for validation and testing. The authors also presented heat exchanger (HEX) modeling methodology where these HEXs were discretized into series of equal temperature or equal enthalpy increments.

\section{Discussion and Conclusions}

The application of $\mu \mathrm{CHP}$ has been shown to reduce primary energy consumption coupled with environmental benefits associated with lower GHG emissions. However, the true savings were shown to be greatly influenced by the control mode adopted: thermal load following vs. electrical load following. Transient heat and power demand variations influenced the overall effectiveness significantly. Therefore, accurate prediction of $\mu \mathrm{CHP}$ output under steady-state as well as transient operating conditions is critical to developing $\mu \mathrm{CHP}$ control schemes and determining the economic viability of their applications. Several researchers developed and tuned the models and approaches to predict the behavior of specific equipment and their integration into buildings. Due to the complexity of the physical processes that take place to produce power in ICE, first principle modeling of $\mu \mathrm{CHP}$ is impractical to implement for building applications. It would require level of details that are usually not available to users. Therefore, all $\mu \mathrm{CHP}$ energy simulation models fall into either grey-box or black box category. Both categories require the availability of performance data of the $\mu \mathrm{CHP}$ system under investigation for calibrating the parameters of the model. Grey-box models are more versatile. The same set of equations can be directly used for different $\mu \mathrm{CHP}$ systems and can be easily modified to accommodate differences in system topography. Black-box models on the other hand are easier to develop. However, a black-box model architecture that is developed for certain system may not apply to a different system.

A summary of the modeling strategies, optimization approaches, benefits and advantages of different studies discussed in Section 2 is outlined in Table 3. 
Table 3. Summary of different modeling methodologies reviewed in the paper.

\begin{tabular}{|c|c|c|c|c|c|}
\hline Prime Mover, (kW) & Energy Storage & Approach/Methodology & Advantages & Optimization & Ref \\
\hline $\begin{array}{l}\text { Combustion Engines, } \\
\text { Fuel Cells }\left(<15 \mathrm{~kW}_{\mathrm{e}}\right)\end{array}$ & Hot water storage tank & $\begin{array}{l}\text { Control Volume. Model } \\
\text { calibration with empirical data }\end{array}$ & $\begin{array}{l}\text { Simplicity, reliability if empirical data } \\
\text { is utilized }\end{array}$ & $\begin{array}{l}\text { Thermal capacitance and conductance } \\
\text { optimization with GenOpt }\end{array}$ & [13] \\
\hline ICE, $5.5 \mathrm{~kW}$ e & $\begin{array}{l}\text { Simulation in TRNSYS, } \\
\text { ESP-r, Energyplus }\end{array}$ & $\begin{array}{l}\text { Annex } 42 \text { model-based control } \\
\text { volume approach }\end{array}$ & $\begin{array}{l}\text { Non-traditional calibration } \\
\text { procedure-using optimization tools }\end{array}$ & $\begin{array}{l}\text { single- and multi-objective } \\
\text { optimization algorithms }\end{array}$ & [14] \\
\hline ICE, $6 \mathrm{~kW}_{\mathrm{e}}$ & Hot water tank & $\begin{array}{l}\text { Annex } 42 \text { modelling approach. } \\
\text { Electric load following mode }\end{array}$ & $\begin{array}{l}\text { Detailed calibration methodology, } \\
\text { Transient mode considerations }\end{array}$ & GenOpt optimization approach & {$[15,16]$} \\
\hline ICE, $6 \mathrm{~kW}$ e & $\begin{array}{l}\text { Variable capacitance hot } \\
\text { water storage tank }\end{array}$ & $\begin{array}{l}\text { TRNSYS dynamic platform, } \\
\text { control volume approach }\end{array}$ & $\begin{array}{l}\text { Parametric study similar to } 14 \text {; } \\
\text { Sensitivity of energy flow with variable } \\
\text { thermal storage volume }\end{array}$ & $\begin{array}{l}\text { Electrical and thermal load following } \\
\text { modes of operation to optimize } \\
\text { the savings }\end{array}$ & [17] \\
\hline Otto cycle Engine, $4 \mathrm{~kW}$ & $\begin{array}{l}\text { Hot water storage tank, } \\
\text { stratified model }\end{array}$ & $\begin{array}{l}\text { TRNSYS component- } \\
\text { based model. }\end{array}$ & $\begin{array}{l}\text { Detailed transient test approaches and } \\
\text { their implications on model reliability }\end{array}$ & $\begin{array}{l}\text { Model tuned to match simulated } \\
\text { outputs with experimental results }\end{array}$ & [19] \\
\hline ICE, $25 \mathrm{~kW}_{\mathrm{e}}, \mathrm{CCHP}$ & $\begin{array}{l}\text { TRNSYS hot water } \\
\text { storage tank module- } \\
\text { based model }\end{array}$ & $\begin{array}{l}\text { Modified Annex } 42 \text { approach } \\
\text { with additional control volume } \\
\text { preventing overheating via } \\
\text { bypass loop }\end{array}$ & $\begin{array}{l}\text { Models ability to operate in manual, } \\
\text { thermal priority and electrical priority } \\
\text { modes. High level of model detail and } \\
\text { calibration methodology }\end{array}$ & $\begin{array}{l}\text { Dynamic simulation model without the } \\
\text { need for any optimization }\end{array}$ & [21] \\
\hline $\begin{array}{l}\text { Reciprocating Gas Engine, } \\
1.3 \mathrm{MW}_{\mathrm{e}}\end{array}$ & Thermal storage tanks & $\begin{array}{l}\text { Dynamic and steady-state } \\
\text { performance data from an } \\
\text { operating plant was used to } \\
\text { develop the model using } \\
\text { engineering principles }\end{array}$ & $\begin{array}{l}\text { Reliable dynamic } \\
\text { performance prediction }\end{array}$ & - & [22] \\
\hline ICE, $<50 \mathrm{~kW}_{\mathrm{e}}$ & $\begin{array}{l}\text { Thermal and } \\
\text { Electrical Storage }\end{array}$ & $\begin{array}{l}\text { Six different components } \\
\text { (including user demand) } \\
\text { in the CHP were } \\
\text { independently modeled }\end{array}$ & $\begin{array}{l}\text { Implementation of delay subsystem } \\
\text { yields high transient } \\
\text { performance reliability. }\end{array}$ & $\begin{array}{l}\text { Optimal thermal and electrical energy } \\
\text { storage-based configurations. } \\
\text { Simplified representation of } \\
\text { dynamic effects }\end{array}$ & {$[24,25]$} \\
\hline Otto Engine, $125 \mathrm{~kW}_{\mathrm{e}}$ & $\begin{array}{l}\text { Stratified thermal } \\
\text { storage module }\end{array}$ & $\begin{array}{l}\text { Three different levels of } \\
\text { stratification were modeled along } \\
\text { with all energy flows }\end{array}$ & $\begin{array}{l}\text { Influence of temperature level in the } \\
\text { tank on energy efficiency and } \\
\text { economics is modeled }\end{array}$ & - & [28] \\
\hline $\begin{array}{l}\text { ICE-ORC Hybrid, } \\
2.5-5 \mathrm{MW}\end{array}$ & None & $\begin{array}{l}\text { ODEs representing conservation } \\
\text { laws while using reliable heat } \\
\text { transfer correlations such as } \\
\text { Wiebe, Woschini, and Annand }\end{array}$ & $\begin{array}{l}\text { Provides guidelines on suitable ICE } \\
\text { designsfor waste heat recovery projects }\end{array}$ & Whole system optimization framework. & [33] \\
\hline Generic CHP Model & $\begin{array}{l}\text { Flexible design } \\
\text { consideration }\end{array}$ & $\begin{array}{l}\text { Based on Mixed-Integer Non } \\
\text { LinearProgramming (MINLP) }\end{array}$ & $\begin{array}{l}\text { Generic dynamic modeling approach. } \\
\text { Provides guidelines for system } \\
\text { definition, and specification. }\end{array}$ & $\begin{array}{l}\text { Generic, low computational } \\
\text { effort framework }\end{array}$ & [38] \\
\hline
\end{tabular}


Table 3. Cont

\begin{tabular}{|c|c|c|c|c|c|}
\hline Prime Mover, (kW) & Energy Storage & Approach/Methodology & Advantages & Optimization & Ref \\
\hline ICE, $15 \mathrm{~kW}_{\mathrm{e}}$ & $\begin{array}{l}\text { Waste heat recovery and } \\
\text { direct utilization }\end{array}$ & $\begin{array}{l}\text { Modeled according to the } \\
\text { continuity, momentum, } \\
\text { and energy equations through } \\
\text { 1D thermo-fluid } \\
\text { dynamic characterization }\end{array}$ & $\begin{array}{l}\text { Flexible waste heat recovery system } \\
\text { with multiple temperature levels of } \\
\text { thermal output }\end{array}$ & $\begin{array}{l}\text { Optimal sizing of the polygeneration } \\
\text { plant based on flexible heat recovery }\end{array}$ & [41] \\
\hline Otto Engine, $4 \mathrm{~kW}_{\mathrm{e}}$ & $\begin{array}{l}\text { Stratified storage } \\
\text { tank model }\end{array}$ & $\begin{array}{l}\text { TRNSYS component based model, } \\
\text { calibrated with empirical data }\end{array}$ & $\begin{array}{l}\text { Application of commercial software to } \\
\text { design, optimize and validate a } \\
\text { complete residential building } \\
\text { CHP system }\end{array}$ & TRNSYS optimization & [43] \\
\hline $\begin{array}{l}\text { Hybrid ICE-Stirling, } \\
85 \mathrm{~kW}_{\mathrm{e}}\end{array}$ & Direct heat utilization & $\begin{array}{l}\text { Zero-dimensional mathematical } \\
\text { model with single zone } \\
\text { consisting of operating fluid as } \\
\text { the thermodynamic system }\end{array}$ & $\begin{array}{l}\text { Simplified system representation with } \\
\text { high reliability }\end{array}$ & $\begin{array}{l}\text { Electrical output optimization via waste } \\
\text { heat utilization in secondary power } \\
\text { generation unit }\end{array}$ & [46] \\
\hline $\begin{array}{l}\text { Biogas-Diesel ICE, } \\
3.5 \mathrm{~kW}_{\mathrm{e}}\end{array}$ & No thermal storage & $\begin{array}{l}\text { Artificial Neural Network (ANN) } \\
\text { based approach while } \\
\text { minimizing the RMSE value }\end{array}$ & $\begin{array}{l}\text { Reliable engine performance prediction } \\
\text { showing the electrical and } \\
\text { thermal outputs }\end{array}$ & $\begin{array}{l}\text { Iterative selection data optimization for } \\
\text { ANN design optimization. }\end{array}$ & [47] \\
\hline $\begin{array}{l}\text { 3MWe, } \\
\text { polygeneration system }\end{array}$ & None & $\begin{array}{l}\text { Open Problem Table (OPT) } \\
\text { combining pinch analysis } \\
\text { with MILP }\end{array}$ & $\begin{array}{l}\text { Novel approach for complex systems } \\
\text { containing multiple sources and sinks }\end{array}$ & $\begin{array}{l}\text { MILP model with multiple } \\
\text { decision variables }\end{array}$ & [48] \\
\hline
\end{tabular}


The Annex 42 model, which falls in the grey-box category, is the most widely adopted model to simulate the energy performance of $\mu \mathrm{CHP}$. The model reflects the underlying physical processes while relying on parametric equations relating inputs and outputs. This model has been independently calibrated and validated for numerous ICE based $\mu \mathrm{CHP}$ systems. However, further development is required to improve the impact of transients such as start-up and shutdown on the model's thermal predictions. Accuracy of thermal capacitance and overall thermal conductivity of the components in various control systems is necessary for a reliable model. Despite the availability of several publications that reported on the experimental calibration of the Annex 42 model, there remains a need to develop procedure for that calibration. Furthermore, the time step of the calibrated model was not addressed in any of those publications. Buildings energy simulation models typically run larger time steps than physics models. Available literature did not address how large of a time step could be used while still maintaining numerical stability of the $\mu \mathrm{CHP}$ model solution. There is a need to investigate that issue and how it affects the sampling rate of the experimental data. Modeling strategies and methodologies prescribed in the work presented in $[15,16,19,21,24,25,33,38,48]$ provide invaluable guidance towards designing and optimizing $\mu \mathrm{CHPs}$ and their hybrid configurations using renewable sources.

Based on the reviewed work, the authors suggest a closer look in to the following topics to help cement the $\mu \mathrm{CHP}$ as an efficient and resilient energy source to address the growing needs of the population driven by economy and new energy consumers entering the marketplace (e.g., electric vehicles). Thorough consideration of the following aspects in the model is recommended for enhancing the reliability and predictability of a global $\mu \mathrm{CHP}$ model:

- Develop/refine models to address discrepancies associated with transient behavior-startup, cool-down, stand-by, interval between start and stop cycles, and delay time in these transient conditions. These aspects have been shown to improve the thermal efficiency of the system and are crucial for a reliable model.

- Develop reliable schemes to analyze the performance of thermal and electric energy storage modules over a broad range of operating conditions. These models must be designed such that the integration-related discrepancies are accounted for appropriately.

- Properly account for condensation of the flue gas exhaust stream in the PM model as well as its integration with thermal storage model

- Simulation results have been proven to be impacted significantly by the time-step used in the model. This factor must be considered for developing the model and utilizing the calibration data in a meaningful form

- Broader operational and experimental results need to be collected to study and characterize the PM thoroughly

- Storage system model must balance the accuracy of the PM model

- System design approaches focusing on cold climate applications- $\mu \mathrm{CHP}$ systems are ideal resources for cold climate applications where the heat demand is high, and the grid resources are vulnerable

- Thorough consideration of the governing physics and chemistry of the model to improve the accuracy of complex systems

- Expansion of the $\mu \mathrm{CHP}$ model to integrate thermally driven heat pump technology for maximizing the energy efficiency

- Examination of co/trigeneration system models for applications in communities, non-residential buildings, and other large facilities

- Application of these models to address commercialization issues to help wider market adoption.

The last two decades have witnessed a significant amount of work aimed at developing reliable mathematical models of $\mu \mathrm{CHP}$ systems, their application in real world scenarios and understanding the complexities associated with integration into the building environment. Development opportunities surrounding the modeling of prime movers and their integration with energy storage technologies 
were identified by several researchers. Publically available software platforms have evolved to design, improvise, and develop reliable cogeneration simulation models which will aid in further development of reliable, efficient, and resilient $\mu \mathrm{CCHP}$ products.

Energy utilization in buildings is a challenging subject, influenced by the building's thermal and electrical demands, and primarily impacted by mismatch between the energy demand and supply. As a result, energy storage must be an integral part of the $\mu \mathrm{CHP}$ system to fully utilize the benefits of distributed generation. A fully integrated optimal $\mu \mathrm{CHP}$ configuration is underexplored as there are numerous possible solutions, which leads to the need to utilize software programs that help design the ideal system.

Author Contributions: P.C. carried out the concept paper development, conducted the literature study, prepared the paper structure, aim, objectives, research focus, analyzed the literature, as well as writing the paper. A.A.-H. analyzed the available literature, advised on the research gaps and objectives, and proofread the paper. All authors have read and agreed to the published version of the manuscript.

Funding: This research was funded by Building Technologies Office, U.S. Department of Energy, grant number NFE-19-07946.

Acknowledgments: This research was supported by the DOE Office of Energy Efficiency and Renewable Energy (EERE), Building Technologies Office and used resources at the Building Technologies Research and Integration Center, a DOE-EERE User Facility at Oak Ridge National Laboratory.

Conflicts of Interest: The authors declare no conflict of interest.

\section{Nomenclature}

$\begin{array}{ll}\text { CHP } & \text { Combined Heat and Power } \\ \text { DG } & \text { Distributed Generation } \\ \text { EES } & \text { Electric Energy Storage } \\ \text { GHG } & \text { Green House Gas } \\ \text { HX } & \text { Heat Exchanger } \\ \text { ICE } & \text { Internal Combustion Engine } \\ \text { IEA } & \text { International Energy Agency } \\ \text { kW } & \text { Kilo Watts } \\ \mu \text { CHP } & \text { Micro CHP } \\ \text { MW } & \text { Mega Watts } \\ \text { NG } & \text { Natural Gas } \\ \text { ORC } & \text { Organic Rankine Cycle } \\ \text { PEMFC } & \text { Proton Exchange Membrane Fuel Cell } \\ \text { PHX } & \text { Plate Heat Exchanger } \\ \text { PM } & \text { Primary Mover } \\ \text { RPM } & \text { Revolutions Per Minute } \\ \text { SOFC } & \text { Solid Oxide Fuel Cell } \\ \text { TES } & \text { Thermal Energy Storage } \\ \text { TRNSYS } & \text { Transient System Simulation Tool } \\ \text { HEX } & \text { Heat Exchanger } \\ \text { Symbols } & \\ \text { a: b } & \text { Coefficients } \\ \text { A } & \text { Area } \\ \text { C } & \text { Thermal conductance } \\ \text { cp } & \text { Specific heat at constant pressure } \\ \partial & \text { Partial derivative } \\ \text { E } & \text { Energy } \\ H & \text { Enthalpy } \\ \text { L } & \text { Length } \\ \text { MC } & \text { Bulk thermal capacitance } \\ \text { m } & \text { Mass } \\ \eta & \text { Efficiency } \\ & \end{array}$




$\begin{array}{ll}\mathrm{P} & \text { Power } \\ Q & \text { Heat energy } \\ \mathrm{r} & \text { Radius } \\ \mathrm{Re} & \text { Reynolds number } \\ t & \text { time } \\ \mathrm{T} & \text { Temperature } \\ \tau & \text { Time Delay Constant } \\ \mathrm{U} & \text { Heat transfer coefficient } \\ x & \text { Concentration }\end{array}$

\section{References}

1. Combined Heat and Power (CHP) Technical Potential in the United States. Available online: https://www.energy. gov/sites/prod/files/2016/04/f30/CHP\%20Technical\%20Potential\%20Study\%203-31-2016\%20Final.pdf (accessed on 12 February 2020).

2. Icerman, L.; Staples, D. Industrial cogeneration: Problems and promise. Energy 1979, 4, 101-117. [CrossRef]

3. Dorer, V. Review of Existing Residential Cogeneration Systems Performance Assessments and Evaluations: A Report of Subtask C of FC+ COGEN-SIM: The Simulation of Building-integrated Fuel Cell and Other Cogeneration Systems-Annex 42 of the International Energy Agency Energy Conservation in Buildings and Community Systems Programme; Natural Resources Canada: Ottawa, ON, Canada, 2007.

4. De Paepe, M.; D’Herdt, P.; Mertens, D. Micro-CHP systems for residential applications. Energy Convers. Manag. 2006, 47, 3435-3446. [CrossRef]

5. Dorer, V.; Weber, A. Energy and $\mathrm{CO}_{2}$ emissions performance assessment of residential micro-cogeneration systems with dynamic whole-building simulation programs. Energy Convers. Manag. 2009, 50, 648-657. [CrossRef]

6. Wu, D.; Wang, R. Combined cooling, heating and power: A review. Prog. Energy Combust. Sci. 2006, 32, 459-495. [CrossRef]

7. Few, P.; Smith, M.; Twidell, J. Modelling of a combined heat and power (CHP) plant incorporating a heat pump for domestic use. Energy 1997, 22, 651-659. [CrossRef]

8. Jalalzadeh-Azar, A.A. A comparison of electrical-and thermal-load-following CHP systems. ASHRAE Trans. 2004, 110, 85.

9. Peacock, A.; Newborough, M. Controlling micro-CHP systems to modulate electrical load profiles. Energy 2007, 32, 1093-1103. [CrossRef]

10. Lund, H.; Münster, E. Modelling of energy systems with a high percentage of CHP and wind power. Renew. Energy 2003, 28, 2179-2193. [CrossRef]

11. Houwing, M.; Ajah, A.N.; Heijnen, P.W.; Bouwmans, I.; Herder, P.M. Uncertainties in the design and operation of distributed energy resources: The case of micro-CHP systems. Energy 2008, 33, 1518-1536. [CrossRef]

12. Henning, D. Cost minimization for a local utility through $\mathrm{CHP}$, heat storage and load management. Int. J. Energy Res. 1998, 22, 691-713. [CrossRef]

13. Beausoleil-Morrison, I. Specifications for Modelling Fuel Cell and Combustion-Based Residential Cogeneration Devices within Whole-Building Simulation Programs; International Energy Agency, Swiss Federal Laboratories: Dübendorf, Switzerland, 2008.

14. Ferguson, A.; Kelly, N.; Weber, A.; Griffith, B. Modelling residential-scale combustion-based cogeneration in building simulation. J. Build. Perform. Simul. 2009, 2, 1-14. [CrossRef]

15. Rosato, A.; Sibilio, S. Calibration and validation of a model for simulating thermal and electric performance of an internal combustion engine-based micro-cogeneration device. Appl. Therm. Eng. 2012, 45, 79-98. [CrossRef]

16. Rosato, A.; Sibilio, S. Energy performance of a micro-cogeneration device during transient and steady-state operation: Experiments and simulations. Appl. Therm. Eng. 2013, 52, 478-491. [CrossRef]

17. Rosato, A.; Sibilio, S.; Scorpio, M. Dynamic performance assessment of a residential building-integrated cogeneration system under different boundary conditions. Part I: Energy analysis. Energy Convers. Manag. 2014, 79, 731-748. [CrossRef] 
18. Schütz, T.; Streblow, R.; Müller, D. A comparison of thermal energy storage models for building energy system optimization. Energy Build. 2015, 93, 23-31. [CrossRef]

19. Lee, H.; Bush, J.; Hwang, Y.; Radermacher, R. Modeling of micro-CHP (combined heat and power) unit and evaluation of system performance in building application in United States. Energy 2013, 58, 364-375. [CrossRef]

20. Gu, W.; Wu, Z.; Bo, R.; Liu, W.; Zhou, G.; Chen, W.; Wu, Z. Modeling, planning and optimal energy management of combined cooling, heating and power microgrid: A review. Int. J. Electr. Power Energy Syst. 2014, 54, 26-37. [CrossRef]

21. Zheng, C.Y.; Wu, J.Y.; Zhai, X.Q.; Yang, G.; Wang, R.Z. Experimental and modeling investigation of an ICE (internal combustion engine) based micro-cogeneration device considering overheat protection controls. Energy 2016, 101, 447-461. [CrossRef]

22. Wang, Y.; Bermukhambetova, A.; Wang, J.; Lv, J.; Gao, Q. Dynamic modelling and simulation study of a university campus CHP power plant. In Proceedings of the 2014 20th International Conference on Automation and Computing, Philadelphia, PA, USA, 12-13 September 2014; pp. 3-8.

23. Rey, G.; Ulloa, C.; Cacabelos, A.; Barragáns, B. Performance analysis, model development and validation with experimental data of an ICE-based micro-CCHP system. Appl. Therm. Eng. 2015, 76, 233-244. [CrossRef]

24. Ippolito, F.; Venturini, M. Micro-CHP System Transient Operation in a Residential User Microgrid. In Proceedings of the ECOS 2017, San Diego, CA, USA, 2-6 July 2017; pp. 1-16.

25. Ippolito, F.; Venturini, M. Development of a Simulation Model of Transient Operation of Micro-Combined Heat and Power Systems in a Microgrid. J. Eng. Gas Turbines Power 2018, 140, 032001. [CrossRef]

26. Portoraro, A.; Ruscica, G.; Badami, M. Micro-Cogenerazione nel Settore Residenziale con l'utilizzo di Motori a Combustione Interna: Sviluppo di un Modello Matematico per la Simulazione Oraria e Analisi di un Caso Reale; Report No. RdS/2010/227; Ministero Dello Sviluppo Economico: Rome, Italy, 2010. (In Italian)

27. Ippolito, F.; Venturini, M. Micro Combined Heat and Power System Transient Operation in a Residential User Microgrid. J. Energy Resour. Technol. 2019, 141, 042006. [CrossRef]

28. Campos Celador, A.; Odriozola, M.; Sala, J.M. Implications of the modelling of stratified hot water storage tanks in the simulation of CHP plants. Energy Convers. Manag. 2011, 52, 3018-3026. [CrossRef]

29. Thomas, B. Experimental determination of efficiency factors for different Micro-CHP units according to the standard DIN 4709. Appl. Therm. Eng. 2014, 71, 721-728. [CrossRef]

30. Xie, D.; Chen, A.; Gu, C.; Tai, J. Time-domain modeling of grid-connected CHP for its interaction with the power grid. IEEE Trans. Power Syst. 2018, 33, 6430-6440. [CrossRef]

31. Mednikov, A.; Maksimov, A.; Tyurina, E. Mathematical modeling of mini-CHP based on biomass. In Proceedings of the E3S Web of Conferences, Irkutsk, Russia, 4-7 June 2018; p. 02005.

32. Ma, X.; Cai, L.; Meng, Q.; Chen, T.; Zhang, X. Dynamic optimal control and economic analysis of a coaxial parallel-type hybrid power gas engine-driven heat pump. Appl. Therm. Eng. 2018, 131, 607-620. [CrossRef]

33. Chatzopoulou, M.A.; Markides, C.N. Thermodynamic optimisation of a high-electrical efficiency integrated internal combustion engine-Organic Rankine cycle combined heat and power system. Appl. Energy 2018, 226, 1229-1251. [CrossRef]

34. Hamzehkolaei, F.T.; Amjady, N. A techno-economic assessment for replacement of conventional fossil fuel based technologies in animal farms with biogas fueled CHP units. Renew. Energy 2018, 118, 602-614. [CrossRef]

35. Wang, Y.; Wang, X.; Yu, H.; Huang, Y.; Dong, H.; Qi, C.; Baptiste, N. Optimal design of integrated energy system considering economics, autonomy and carbon emissions. J. Clean. Prod. 2019, 225, 563-578. [CrossRef]

36. Mărcuş, G.; Iordache, V.; Iordache, F.; Ilie, A. Energy analysis of a CHP plant with internal combustion engines, for a district heating system, based on the information from the annual database. In Proceedings of the E3S Web of Conferences, Cluj Napoca, Romania, 22 February 2019; Volume 85, p. 01012.

37. Badami, M.; Chicco, G.; Portoraro, A.; Romaniello, M. Micro-multigeneration prospects for residential applications in Italy. Energy Convers. Manag. 2018, 166, 23-36. [CrossRef]

38. Rech, S. Smart energy systems: Guidelines for modelling and optimizing a fleet of units of different configurations. Energies 2019, 12, 1320. [CrossRef]

39. Costa, M.; Rocco, V.; Caputo, C.; Cirillo, D.; Di Blasio, G.; La Villetta, M.; Martoriello, G.; Tuccillo, R. Model based optimization of the control strategy of a gasifier coupled with a spark ignition engine in a biomass powered cogeneration system. Appl. Therm. Eng. 2019, 160, 114083. [CrossRef] 
40. Yang, Y.; Cai, L.; Chen, T.; Zhou, Q.; Zhang, X. A Study of Hybrid-Power Gas Engine-Driven Heat Pump Control Strategy Based on Instantaneous Optimization. In Proceedings of the IOP Conference Series: Earth and Environmental Science, August 2019, West Java, Indonesia, 29 August 2019; p. 032067.

41. Gimelli, A.; Muccillo, M. Performance assessment of a $15 \mathrm{~kW}$ Micro-CHCP plant through the 0D/1D thermo-fluid dynamic characterization of a double water circuit waste heat recovery system. Energy 2019, 181, 803-814. [CrossRef]

42. Morrone, P.; Algieri, A.; Castiglione, T.; Perrone, D.; Bova, S. Investigation of the energy performance of multi-source integrated CHP systems for small-scale applications. In Proceedings of the AIP Conference Proceedings, Grenoble, France, 8 July 2019; p. 020115.

43. Jung, Y.; Kim, J.; Lee, H. Multi-criteria evaluation of medium-sized residential building with micro-CHP system in South Korea. Energy Build. 2019, 193, 201-215. [CrossRef]

44. Krieger, M.; Stecklair, D.; Peluso, S.; Stockar, S. Design and Verification of a Small-Scale District Heating Network Experiment. In Proceedings of the Dynamic Systems and Control Conference, Anaheim, CA, USA, 8 October 2018; p. V002T023A002.

45. Trninic, M.; Todorovic, D.; Jovovic, A.; Stojiljkovic, D.; Skreiberg, Ø.; Wang, L.; Manic, N. Mathematical Modelling and Performance Analysis of a Small-Scale Combined Heat and Power System Based on Biomass Waste Downdraft Gasification; Springer: Cham, Switzerland, 2018; pp. 159-173.

46. Sheykhi, M.; Chahartaghi, M.; Balakheli, M.M.; Hashemian, S.M.; Miri, S.M.; Rafiee, N. Performance investigation of a combined heat and power system with internal and external combustion engines. Energy Convers. Manag. 2019, 185, 291-303. [CrossRef]

47. Akkouche, N.; Loubar, K.; Nepveu, F.; Kadi, M.E.A.; Tazerout, M. Micro-combined heat and power using dual fuel engine and biogas from discontinuous anaerobic digestion. Energy Convers. Manag. 2020, 205, 112407. [CrossRef]

48. Pina, E.A.; Lozano, M.A.; Ramos, J.C.; Serra, L.M. Tackling thermal integration in the synthesis of polygeneration systems for buildings. Appl. Energy 2020, 269, 115115. [CrossRef]

49. Olympios, A.V.; Le Brun, N.; Acha, S.; Shah, N.; Markides, C.N. Stochastic real-time operation control of a combined heat and power (CHP) system under uncertainty. Energy Convers. Manag. 2020, 216, 112916. [CrossRef]

50. Chen, Y.; Wang, J.; Lund, P.D. Thermodynamic performance analysis and multi-criteria optimization of a hybrid combined heat and power system coupled with geothermal energy. Energy Convers. Manag. 2020, 210, 112741. [CrossRef]

51. Olympios, A.V.; Pantaleo, A.M.; Sapin, P.; Markides, C.N. On the value of combined heat and power (CHP) systems and heat pumps in centralised and distributed heating systems: Lessons from multi-fidelity modelling approaches. Appl. Energy 2020, 274, 115261. [CrossRef] 